This is the peer-reviewed but unedited manuscript version of the following article:

Karimi-Aghdam, S. (2016). Rethinking Vygotskian cultural-historical theory in light of Pepperian root metaphor theory: Dynamic interplay of the organicism and contextualism. Human Development. http://www.karger.com/Journal/Home/224249

The final, published version is available at http://www.karger.com

\title{
Rethinking Vygotskian Cultural-Historical Theory in Light of Pepperian \\ Root Metaphor Theory: Dynamic Interplay of the Organicism and Contextualism
}

Saeed Karimi-Aghdam

Department of Languages, University of Jyväskylä, Jyväskylä, Finland $\underline{\text { saeed.karimi-aghdam@jyu.fi }}$

\section{Key Words}

Vygotskian Cultural-Historical Theory. Root Metaphor Theory. Contextualism. Organicism. Dialectic. Pepper. Causality. World View. Emergence. Subjective Psychology. Objective Psychology.

\section{Abstract}

This article examines Vygotskian cultural-historical theory by putting it into dialogue with Stephen Pepper's root metaphor theory. I focus on Vygotsky's insistence on the dialectical unity 
of the phylogenetic and ontogenetic domains in ontogenesis, which he expressed in his account of how the 'natural-psychological' and 'cultural-psychological' lines of development merge with the emergence of language in ontogenesis. I compare Vygotsky's two genetic domains and Pepper's world hypotheses of organicism and contextualism. I argue that Vygotsky transcended what is often thought of as a fundamental dichotomy between organicism and contextualism. In accomplishing this effective reconciliation, Vygotsky demonstrated that it is possible both to traverse the ontological schism between subjective psychology and objective psychology, and to foreground the contingent, complex, dynamic, emergent, and mediated nature of human consciousness.

The aim of this paper is to make explicit features of Vygotskian cultural-historical theory [CHT] that have previously been ignored. In pursuing this aim I will draw on a comparison between Vygotsky's two genetic domains [i.e., the natural and the cultural] and Stephen Pepper's [1942] world hypotheses -conceptual systems that describe several alternative ontological world views. The argument to be pursued is that Vygotsky through employing a dialectical method was able to synthesize ostensibly contradictory tenants of contextualism and organicism world hypotheses into a dynamic unified and relational whole. Panoramic perspectives of the ultimate nature of the empirical reality and ways of looking at the world have profound implications for every aspect of research from data collection to theory construction, and hypothesis testing. Therefore, developmental psychologists have been engaged in highlighting the influence of world hypotheses and their associated underpinnings and presuppositions on theory construction and the methodological apparatus of their theoretical models [e.g., Reese \& Overton, 1970; Overton \& Reese, 1973; Overton, 1984, 1998]. 
Although Vygotsky's CHT is one of the most fruitful and productive developmental theories, it is scarcely an exaggeration to say that it has not received due attention that it deserves being subjected to a rigorous and systematic analysis of its ontological and epistemological assumptions [see also Stetsenko, 2009; Stetsenko \& Arievitch, 2004]. There are, however, some minor suggestions in the literature [e.g., Overton, 2012, 2014] and some disagreements as to which of Pepper's world hypotheses is most consistent with Vygotsky's CHT. For example, Overton [2012] suggested Vygotsky's CHT is representative of the 'organicism' metaphysical school of thought; however in a recent publication [Overton, 2015] he argues that Vygotsky's CHT is an example of a 'process-relational' philosophical position. On the other hand, Rogoff [1982] has emphasized that Vygotsky's CHT falls squarely into a contextual event [transactional] approach or Pepper's contextualism world hypothesis. Rogoff has stated, 'Consistent with the contextual event approach, these theorists [Gibsons, Vygotsky and Leont'ev] emphasize that cognitive activity cannot ultimately be conceived of as characteristic of the person separate from the context in which the person thinks' [1982, p. 134]. Likewise, Moshman [1982] maintains that Vygotskian CHT is lodged in the contextualism world hypothesis. Cole [1996], to reach a conceptualization of context as a 'process of weaving together', made use of Pepper's contextualism world hypothesis. Cole [1997] further pointed out that cultural-historical psychology is a fusion of two Pepperian world hypotheses, i.e. organicism and contexualism 'because humans just are hybrids of the two principles of development' [p.247, italics in original].

In this paper I argue that Vygotsky's CHT has self-consciously drawn upon a dialectical movement and relational epistemology to undermine the dualistic clash of contextualist (i.e., the social-historical) and organismic (i.e., the individual-biological) thinking about human 
development [see also Bidell, 1988; Ratner, 1991]. The application of dialectical and historical materialism to the psychological subject matter is one of the keystones of Vygotsky's CHT of higher mental processes (i.e., uniquely human-centered processes) [Vygotsky, 1978, 1998]. Vygotsky by invoking dialectical epistemology offers a developmental theory which eschews the pitfalls of reducing human development and consciousness to a maturation of a biological 'organism' or reducing human consciousness to an epiphenomenon of extrasomatic influences of the social-historical umwelt [e.g., see Stetsenko \& Arievitch, 2004;Collins, 2000].

Vygotsky's CHT, in this article I purport to demonstrate, is an example, par excellence, of a developmental theory which has translated the synthetic fusion of the assumptions and basic categories of organicism and contextualism as world hypotheses into a coherent and comprehensive frame of reference for understanding, describing, explaining, and optimizing human developmental processes. Vygotsky's CHT maintains that a dynamic interfusion of 'cultural-historical context' with 'the biological-natural aspect of an organism' transforms the human being from being a passive 'biological animal' with lower-level functions into an active 'cultured human' with higher-level functions. This does not warrant any conclusion as to prior disparate montage, or sundered existence, of the biological and the cultural processes of human development. Instead, the cultural and the biological processes exist for one another but also by means of one another being 'merged in ontogenesis and actually form a single, although complex process' [Vygotsky, 1997c, p. 15]. Vygotsky's CHT indicates that the genetic roots of the human higher-level functions and processes emerge out of the interpenetrating co-actions of four nested systems, i.e., phylogeny, cultural history, ontogeny, and microgenesis [Wertsch, 1985; Vygotsky, 1987, 1993]. Of particular concern in this article is Vygotsky's affirmation of the relational synthesis of the phylogenetic and ontogenetic domains in the process of ontogenesis, the central 
concern of developmental science [Vygotsky, 1987, 1993; Vygotsky \& Luria, 1929], which he articulated in his account of how the biological and the historical-cultural trajectories coalesce with the emergence of language. By integrating organicism and contextualism world hypotheses into a unified and coherent metatheoretical edifice, I therefore propose to argue that Vygotsky has overcome the traditional dichotomy between subjective-objective psychology, offering an integrative CHT without ontologically divorcing, and positing an independent existence for, the subjective mind (experiencing and knowing individual) and objective world (spatial and temporal attributes and entifications that are independent of experiencing individual).

In the following section RMT is introduced [Pepper, 1928, 1935, 1942, 1943 a]. The next section addresses the legitimacy of integrating Pepperian world hypotheses with particular reference to the developmental science literature. A penultimate section of the paper details the perennial dichotomous debate vacillating between the subjective psychology vis-à-vis objective psychology and shows how Vygotsky's CHT closes the ontological gap between these two polarized camps. Then, the desideratum of the dialectical synthesis of two out of four world hypotheses delineated upon by RMT, viz. organicism and contextualism in construction of Vygotskian CHT is discussed. The paper also examines features of the dialectical logic in Vygotskian CHT that are employed to expound human consciousness as an emergent, complex, mediated and dynamic phenomenon. Finally, some conceptual conclusions will be drawn.

\section{Examining Pepperian Root Metaphor Theory}

Stephen C. Pepper [1891-1972], an American philosopher, introduced root-metaphor theory based on a systematic categorization and typological conceptualization of what he believed to be four equally and relatively adequate 'world hypotheses'[for a cogent elaboration of world view 
from different perspectives see Naugle, 2002]. A world hypothesis is a comprehensive, coherent, corroborated, and conducting set of categories with an unrestricted evidential scope that is about the world itself and seeks out to organize the totality of evidence in conformity with embracing unlimitedly any available range of facts proposed for description and subjecting adequately all evidential items to corroboration [e.g., Pepper, 1943b]. Drawing upon basic and concrete evidential source as the building blocks of rational construction of world hypotheses, Pepper [1942, 1943a] argues that there are only four relatively adequate unrestricted world hypotheses which in turn are anchored on four pivotal root metaphors (i.e., selected sets of common-sense facts and areas of empirical observation): formism, mechanism, contextualism and organicism [for the fifth world hypothesis 'selectivism', see Pepper, 1934, 1966]. The first world hypothesis, formism is based on the root metaphor of similarity between different objects and events, that is, 'the identity of a single form in a multiplicity of particular exemplifications' [Pepper, 1973, p. 198]. The second, root metaphor of mechanism is the machine, that is, 'material push and pull, or attraction and repulsion culminating in the conception of a machine or an electromagneticgravitational field' [Pepper, 1973, p. 198]. The root metaphor of Pepper's third hypothesis of contextualism is an ongoing act of change (i.e., a historic event), that is, 'a transitory historical situation and its biological tensions as exhibited by Dewey and his followers' [Pepper, 1973, p. 198].The root metaphor for the fourth hypothesis of organicims is process of harmonious unity (i.e., an organized whole), that is, 'a dynamic organic whole as elaborated by Hegel and his followers' [Pepper, 1973, p. 198]. As diagrammatic representation below plainly shows Pepper [1942] grouped four world hypotheses into two different categories. Organicism and contextualism are synthetic world hypotheses whereas formism and mechanism are analytical world hypotheses. Moreover, formism and contextualism are dispersive world hypotheses while 
on the contrary mechanism and organicism are integrative world hypotheses. To clarify how and in what respects Vygotskian CHT, a dialectical tertium quid, cuts across organicism and contextualism world hypotheses explicating these two world theories which are 'species of the same theory' [Pepper, 1942, p. 280] in more detail seems imperative.

\begin{tabular}{|c|c|c|}
\hline & Dispersive & Integrative \\
\hline Analytical & Formism & Mechanism \\
\hline Synthetic & Contextualism & Organicism \\
\hline
\end{tabular}

A schematic taxonomy of World Hypotheses adopted from Pepper [1942]

Root metaphor of contextualism as a synthetic world hypothesis is 'an act in its context' (i.e., a historic event) [Pepper, 1942, p. 232]. Historic events do not primarily characterize past events but are relational and interpenetrated activities and incidents whose patterns are changing dynamically based on the contingencies and particularities of the present 'now'; therefore, historic events are ongoing and interconnected acts in their surrounding context constantly concatenating and re-presenting their past (i.e., no-longer present) and future (i.e., not-yet present) [Pepper, 1942, p. 233]. Organicism is also a synthetic world hypothesis with integration (i.e., the organic whole) as its root metaphor. Organicism is on a par with contextualism with respect to being a synthetic world hypothesis. The basic guiding facts and categories of synthetic world hypotheses are complexes or contexts rather than the intrinsic nature of the elements, thus analysis is considered a derivative precipitate of synthesis [Pepper, 1942]. For a synthetic world hypothesis a whole is more than a mereological sum of its elements, is categorically prior to and 
inclusive of the individual parts, and provides a basis for the existence of, and grants liabilities to, its differentiated but internally related elements.

Contextualism, on the other hand, is a 'dispersive' world hypothesis. That is to say, $a$ posteriori observational evidence and reasoning is adduced in this world hypothesis and chance, more or less, is deemed acceptable. Hence scope is more adequate than precision for contextualism. For contextualism, the basic universal structural features are novelty and change of the historic event as it is actually taking place in our present epoch [Pepper, 1942, p. 235]. Any sort of fact is easily real for contextualism without concern for past events; hence, fluid change and novelty are presuppositions of contextualism. As contextualism takes in facts independently of other facts more often than not, unpredictability is in line with its not-highlysystematic system whose order is not unwavering [Pepper, 1935, 1942]. For a contextualist, the dispositional properties of interactive historical events within an organism per se is not enough to explain particular details of dynamic processes of change and motion in concrete tempo-spatial contexts. For a contextualist, the historical properties of an organism are to a considerable degree independent of each other. Subsequently, the structure of the organism is not imposing a preordained pattern or a pre-wired design; for contextualism disorder is a categorical attribute [Pepper, 1928, 1942].

Organicism is an 'integrative' world hypothesis. In other words, justifications and assumptive axioms and postulates which are used in organicism are a priori. As such, in organicism chance is eschewed and consequently precision is considered more important than scope. There are two sides to the categories in organicism. Internal factual contradictions of the progressive steps of organic processes (i.e., the Appearance) and the ideal organic structure to be achieved (i.e., the Reality), spontaneously transcend the bounds of all experiential fragments and 
become integrated. Consequently, an 'absolutely concrete coherent organic whole' inevitably emerges [Pepper, 1942].Organicism maintains its dynamic equilibrium despite erratic environmental perturbations exerted 'here and now' across space and time scales because various system-wide sub-structures have a dispositional property of moving towards some goal. A formal causality -the essential nature of a thing which distinguishes a form from all other things [White, 1990; Overton, 1998] and contributes 'the essence, idea, or quality of the thing concerned' [Bunge, 1962, p. 32] - is drawn upon to explain actual but not-yet-integrated fragments of experience and is invoked to investigate the nature of being. For organicism, the structural progression of a coherent whole (i.e., an organic system) prefigures the pathway for the dialectical integration and harmonization of isolated data into the organic whole. Organicism prospectively targets an ideal endpoint subordinating differentiation and difference to integration and unity.

Progressively moving toward an absolute reality, according to organicism, is implicative of a telos (i.e., an ultimate future and guiding reference in developmental process) and, by implication, brings final causality into causal chains of explanation [see Bunge, 1962; Taylor, 1966]. Final cause is the purpose, goal or 'the end of every generative or motive process' [Bunge, 1962: 32] for which something is done or made and is invoked to examine and describe the process of becoming. The number and order of developmental paths towards organic structure are not finite nor are they preexisting niches or innate dispositional structures. That is, 'the goal [is] predetermined in the structure of the facts, but not the particular path to the goal' [Pepper, 1942, p. 295]. Therefore, all micro-pathways conduce to, and are productive of, the same organic whole. It may not be an undue overstatement to claim that for organicism the emergence of new appearances in developmental trajectories cannot be attributed exclusively to 
neither material nor efficient causal explanatory conceptualizations. Taking this further, it can be argued that emergent properties are irreducible to, and unpredictable in advance of the fact from, their constituent parts [see also Pepper, 1926]. This is, one may argue, because an organismwhile maintaining its unity in terms of formal consistency and material coherence - draws upon organizing dispositions to progress towards 'the absolute'. For organicism with its focus on the final terminus, the integration of changes in the process of development gains towering importance whereas temporal enduring process is demoted to a subsidiary position. For contextualism, on the contrary, commensurate with its focus pivoted on the constantly changing present, admittance of examining development as it is constructed in the creative multiplicity and temporal immediacy of the present stream of experience gains credence. In a move toward articulating one of the main differences between organicism and contexualism, Pepper [1942] offers a similar perspective: '.. organicism has to deal mainly with historic processes even while it consistently explains time away, whereas contextualism has to admit integrative structures surrounding and extending through given events even though these structures engender it categories'.

I tend to stress that the decontextualized investigation of development, based on the organicism world hypothesis, falls short of addressing the actual behaviors of an organism which are embedded and embodied in immediate time and space as well as in its mediate local and temporal historicity. Explaining away efficient (a cause of becoming) and material (a cause of being) causal chains in the development process and endeavoring to explain how categories fit into the underlying abstract ideal structures is still another repercussion of preconceiving, by presupposition, a phenomenal existence rather than a real existence for development. Yet, interpenetrated past and present times nexus from the organicism's vantage point are not given 
due attention and are treated as inconsequential for shaping the prospective unified and harmonious organic whole. Simply and briefly stated, on the other hand, contextualism deregiments analytically, concordant with minutiae of the immediate context, the organized totality of human development into monadic elements and independent properties as parts of a structured whole. Moreover, contextualism divests its explanatory discourses of formal (i.e., cause of being) and final (i.e., cause of becoming) causalities seeing development to devolve toward a continually greater dispersion and disorder rather than to evolve toward a harmonious integration and synthetic unity. Since chance has ontological reality for contextualism and disorder and change are categorical (i.e., non-derivative) features of it [Lerner, Hultsch, \& Dixon, 1983; Pepper, 1942], the patterns of development are constantly changing giving rise to possible creative and genuine novelties rather than to determinate explicative and maturational variations [see also Stace, 1939]. Formal and final causalities that are invoked in organicism render the self-evolving and progressive process of development regulative, meaningful, orderly, and apprehensible both in terms of its current dynamic constellations and its end-directed processual trajectory [Moravcsik, 1974; Overton, 2013c; Rosenblueth, Wiener, \& Bigelow, 1943].

Attributing development en bloc to material and efficient causes which are determinable antecedents and specifiable conditions for temporally and contextually embedded effects that are subsequent in time by virtue of observation as is the case in contextualism implicates that inference and interpretation as well as complete and coherent organizing, systematizing, and synthesizing of the conceivable developmental changes by dint of final and formal causalities, unlike organicism, are given short shrift [see also Baltes, Reese, \& Nesselroade, 1977; Von Wright, 1971; Harré \& Secord, 1972]. Simultaneous and bidirectional influence of cause and 
effect on one another, in consonance with organicism, means constant reversal of temporal precedence of cause over effect and casts doubt on the permanency and univocality of causeeffect correspondence in germinating development. Hence, bringing final causality into play in explanation of development-not predictive in function but ex post facto - is warranted and in turn leads to obviating the need for confining explanatory arguments, mandated by contextualism, to unidirectional and efficient causal relations that are external to organism in which development occurs. Given its attention riveted on particularizing the relation between a dynamic organism and changing environing context per se, contextualism, sitting at variance with organicism, eschews employment of 'universalistic and thus constantly applicable principles of development' [Lerner, 1986, p.67]. Equally, a lack of systematic and comprehensive account of development which is sliced off by a differential epistemology attests to the effect that contextualism 'cannot form the basis for scientifically viable research programs-unless science were to abandon its attempt to establish an organized and systematic body of knowledge, which is unlikely' [Overton, 1984, p. 218].

As indicated above, efficient and final causalities, according to Aristotle's nexus of causes, are causes of becoming while formal and material causalities are causes of being. Since dispersiveness and novelty are among categorical attributes of contextualism, invoking upward causality- efficient causality from basal lower-level functions to higher-level functions- is not enough for explaining emergent properties of human development at different integrative levels and also its ordered and patterned totality. Efficient causality which is all-pervasive cause in scientific explanations in the modern natural sciences is premised on additivity of discrete and corpuscular constituents of a system. Moreover, in efficient causality cause has temporal priority to effect (i.e., temporal contiguity and succession of antecedent and consequent), and is linear 
and unidirectional. It follows that efficient and final causalities may be used for explaining human development and its analysis at different strata and across multiple levels of organization which enjoy multidirectional, complex and reciprocal influences on one another.

To account for differences among theories and to adjudicate on the different levels of explanation, it should be noted that final and formal causalities are conceived to be pivotal for understanding human developmental theories which are primarily affiliated with organicism whereas material and efficient causalities may be invoked to explain phenomena within ambit of developmental theories that are yoked with contexualism and mechanism. The controversy surrounding the role of final level of causality - teleological in character and an inversion of efficient causality in time without juxtaposition of cause and effect - in scientifically robust and uncompromisingly empiricist understanding of human development has resulted in nonadmission of this type of causality in contexualism- governed theories which set out to come to terms with unorganized complexity rather than organized complexity which is coherent and integrative. Since both organicism and contextualism are nonreductionist avoiding reducing constitutive and relational heterochronic levels of a syncretized whole which are nested and perpetually mutating and reciprocating, therefore, theories which address issues at different levels of organization, by the same token, cannot be reduced ontologically to, and explained properly in terms of, the foundational axioms, bedrock laws, philosophical bases and constituent entities of another theory [e.g., see Schaffner, 1967].

It stands to reason to submit that any single developmental theory which puts claims to adequacy in terms of scope and precision should pay attention to drawbacks of opting for a pure world hypothesis. Moreover, underscoring the generative tenets of associated world hypothesis of a developmental theory on an exhaustive interpretation consist in the retrenchment of the 
different levels of explanation to which a 'radical' (i.e., pure) world hypothesis in and of itself appeals. The next section briefly debates tenability of synthesizing two world hypotheses namely, organicism and contextualism with particular reference to developmental science.

\section{World Hypotheses Synthesis: Defensible or Indefensible?}

Weltanschauung (i.e., world view) analysis à la Pepper's [1942] RMT conceptual and evaluative schemes remain current and have been widely used to guide theorizations, develop conceptual frameworks, and unearth pertinent assumptions and undergirding premises of theoretical architectures in various sub-disciplines of psychology and developmental science in particular [e.g., see Hayes, Hayes, \& Reese, 1988; Langer, 1969; Leary, 1994; Lyddon, 1989; Minton, 1992; Morris, 1988; Overton, 1984, 1991, 1998; Overton \& Ennis, 2006; Rosnow \& Georgoudi, 1986; Super \& Harkness, 2003; Witherington, 2007; for a critique of suitability of RMT for psychological theorization, see Smith, 1988; Staddon, 1993].

As indicated above, organicism and contextualism both are synthetic world hypotheses. In other words, for these two world hypotheses wholes are basic facts from which elements and parts are derived; therefore, wholes have ontological priority over uncompounded elements and parts, coordinating the component parts. On the other hand, whereas organicism is an integrative world hypothesis, contextualism is a dispersive world hypothesis. Contextualism treats synthesis dispersively while organicism handles it integratively [Pepper, 1942, 1943a]. If anything, then, these world hypotheses are interlocked but also divergent along specific categorical lines, so as to be properly enunciated as two related but distinct world theories or more prosaically 'contextualism is simply dispersive organicism' [Pepper, 1942; p. 280] and organicism is simply

integrative contextualism. I would argue that Pepper also drives a time wedge to cleave 
organicism and contextualism into two autonomous but congenial world hypotheses. Organicism belittles time whereas contextualism espouses time and temporality as the linchpin of situated interpretation of dynamic present events. For organicism integration and synthesis in the process of development are regarded as its focal point while time-locked duration of the process takes a back seat [Pepper, 1942].

Pepper [1942, 1943b] claimed that eclectic merging and overstepping the boundaries of world hypotheses results in numerous paradoxes and confusions since each autonomous matrix of presuppositions underlying the ultimate nature of reality (i.e., world hypothesis) operates of necessity consistent with distinct and incontrovertible truth criteria. Hence, mixing world hypotheses ineluctably leads to utterly vicious and illegitimate structural corroboration -i.e., corroboration of the factuality of fact with fact [Pepper, 1942, see also Reese \& Overton, 1970; Burtt, 1943]; this is a deep, and has proved to be contentious issue, and thus inevitably provokes continuing discussion in developmental science. Notwithstanding Pepper's [1942] admonitory remarks regarding the pitfalls of hybridization of world hypotheses or what he terms "irrational eclecticism' [p. 341], there have been some psychologists who, one way or another, have tried to interdigitate Pepperian world hypotheses to arrive at a comprehensive paradigmatic framework on which to predicate human developmental theories. For example, Overton [2006] invoking Pepper's RMT argues for two expansive families of world views which are engendered by wedding two world hypotheses. Combining mechanism and contextualism, for example, gives rise to 'spilt world view' while integrating organicism and contexualism yields 'relational world view'.

Vygotskian CHT is a quintessential example of a developmental theory which on the face of it appears to belong to spilt world view (mechanism-contextualism integration), contra main 
thesis of this paper and in accord with Overton's discussion [2006] as evidenced by a construal which is spearheaded among others by Michale Cole and James Wertsch [e.g., Cole, 1996, Cole \& Wertsch, 1996; Wertsch, 1991]. Conceivably one of the main reasons because of which contexualism chameleon tends to be merged with mechanism or organicism- being susceptible to transmutability of its identity as an autonomous world hypothesis with an idiosyncratic criteria of truth- is that 'pure contextualism' generates non-viable and otiose research programs which lack systematicity and a unifying organization to be pursued scientifically [Overton, 1984]. Pepper [1942] has remarked that contextualism is an inconstant world hypothesis 'constantly on the verge of falling back upon underlying mechanistic structures, or of resolving into the overarching implicit integrations of organicism'(p. 235). Overton [2007] similarly affiliates himself to this stance: 'contextualism is an unstable world view, at one moment sliding over into mechanism, at another moment sliding into organicism' [p.154].

According to Lerner and Kauffman [1985] in the extant literature there are two main objections to bringing contextual vantage point into congruence with 'a concept of development which stresses ideas such as normative progression, universality, irreversibility, and final end state': first, development as an idealized process and reference point toward which evolutive and propagative variations move is different from adventitious change; second, all developmental theories mutatis mutandis premise that context is an immanent part of temporal process of development and foregrounding context may not be regarded as a novel contribution but as a secondary matter-of-fact assertion and that as such still one may claim that some contextual developmental theories in principle can be reduced to basic discrete precepts and techniques of conditioning [pp. 312-313]. Likewise, contextualism 'which stresses only the dispersive, chaotic, and disorganized character of life would not readily lend itself to the derivation of a theory of 
development [Lerner and Kauffman, 1985, p. 318]. Yet, that a deeper understanding of psychology entirely in terms of a 'pure' world hypothesis such as contextualism can be gained, Capaldi and Proctor [1994] note, is an unsustainable argument.

Development is a multidimensional, multilayered, nested, time-locked and processual system with 'integrative levels of organization' [e.g., Bunge, 1960; Feibleman, 1954; Novikoff, 1945a] and all levels in development are emergents with novel properties [Campbell, 2009] in and over anisochronous (i.e., taking place in or occupying unequal times and durations) scales. Each emergent level of development (e.g., the biological, the psychological, the sociocultural) is indescribable and unexplainable in terms of processual and material properties of multiple components and processes comprising its attentive sublevels which in turn are harmonized into a syncretized totality. Further, due to dynamic, complex, organized and interpenetrated rhizomaticity of the entire scale of development, every component and process presupposes and constitutes and in turn is presupposed and constituted by its internal relations of a dialectical kind to other components or processes at sub-, meso-, or supra-levels of increasing complexity. In this view every change generates multiplicative changes at multiple levels of development making every subtle variation integrated and appropriated into the whole system rather than being added piecemeal to an incoherent mélange [Lerner, 1996; Schneirla, 1952, Tobach \& Greenberg, 1984]. Dialectical materialism too endorses emergence of novel qualities at enveloping and divers levels of high organization and complexity [for a stimulating discussion of different doctrines of materialism, see Bunge, 1981]. For example, Shirokov [1937] points out:

If we subject it [a living organism] to a purely external analysis into its elements we shall find nothing except physico-chemical processes. But this by no means denotes that life amounts to a simple aggregate of these physico-chemical elements. The particular physico-chemical processes are 
connected in the organism by a new form of movement, and it is in this that the quality of the living thing lies. The new in a living organism, not being attributable to physics and chemistry, arises as the result of the new synthesis, of the new connection of physical and chemical movements. This synthetic process whereby out of the old we proceed to the emergence of the new was understood neither by the mechanists nor the vitalists.... The task of each particular science is to study the unique forms of movement characteristic of that particular level of the development of matter. (p.341, emphasis in the original)

It may be therefore contended that for investigating more adequately different levels and dimensions of development from biology, psychology through culture and history [Bronfenbrenner, 1979; Riegel, 1975] without ontological reduction of one level to another or making untenable inter-level extrapolations and due to qualitative discontinuity between levels and therefore variation in the pertaining factors, mechanisms, processes, principles and even laws operative at each level, we need conceptual differentiations and developmental theories which are built upon, or at least attentive to, different world hypotheses or their principled synthesis. As a result of considerable skepticism about the adequacy of invoking a pure world hypothesis to understand, describe, explain and optimize development with veridical precision and adequate ambit coupled with acknowledgement of 'dynamic interactions' (i.e., correlative coupling) among all integrative levels [Lerner, 1978] many developmental psychologists have concluded that a new synthetic framework is needed. They conclude that both pure contextualism and pure organicism have limitations on both methodological and conceptual grounds in their ability to address the phenomena of development adequately and coherently [for a counterargument see Kendler, 1986; for a rejoinder see Lerner \& Kauffman, 1986]. In line with Overton [1984] and in accord with 'integrative levels of organization', Lerner and Kauffman 
[1985], for example, contended for a principled integration of two world hypotheses, namely contextualism and organicism without committing the fallacy of eclecticism.

Synthesis of contextualism and organicism entails seeing an organism coupled with context and dynamic, bidirectional and fluent coordination or 'reciprocal determination' [Overton \& Reese, 1973] between them as the fundamental process of development. Based on resultant synthetic world view, every temporal level with its unique laws and generative mechanism of change is accounted for by drawing upon relevant positings, presuppositions and appropriate laws. Altman and Rogoff [1987], examining the philosophical and axiological substrates of Pepper's [1942] RMT and Dewey and Bentley's [1949] three philosophical approaches to the 'knowings and knowns', proffer their own world views while advocating synthesizing some complementary aspects of the different world views. Framing the issue differently, Cole [1997] goes so far as to suggest that fusing organicism and contextualism is necessary to describe and explain human development, albeit that he notes it is analytically confusing.

Recently, the debate over RMT and its implications for developmental science along with world hypotheses pro-synthesis discussions have gained new ascendancy. Witherington [2007], in order to chart out current conceptual landscape of dynamic systems perspective, capitalizes mainly on Pepper's [1942] green light to 'postrational eclecticism' (i.e., eclecticism after the fact) rather than 'irrational eclecticism' (i.e., eclecticism before the fact) [p.341] and advocates an integrative rapprochement between organicism and contextualism world hypotheses as the most viable reading of dynamic systems perspective of human development [see also KarimiAghdam, 2016a; Overton, 2007; Witherington \& Heying, 2013]. Similarly, Lerner and Overton [2008] build upon the relational metatheoretical architecture (i.e., synthesis of organicism and 
contextualism) and developmental systems models to illustrate future research avenues in youth developmental studies.

Overton [2015; Overton \& Ennis, 2007] along similar lines has demonstrated that it is possible to offer a coherent and principled synthesis of organicism and contextualism recasting seeming incompatibilities of the ontological and epistemological assumptions of the contextualist behavior-analytic theories and the organismic cognitive-developmental theories into a synthetic complementarity and relational metatheoretical framework and yielding what he refers to as a 'process-relational' world view or scientific paradigm. The ontology of 'process-relational' world view includes 'process, activity, dialectic change, emergence, and necessary organization as fundamental defining categories, but it does not exclude categories of substance, stability, fixity, additivity, and contingent organization' [Overton, 2013a, p. 42]. Overton [2015] drawing upon a dialectical logic - 'a kind of dynamic monism' [Tucker, 1961, p. 59] - has persuasively argued that in process-relational architectonic matrix in sharp contrast with the Cartesian-splitmechanistic scientific paradigm false dichotomies of pure forms which are conceived to be exclusive hard-cores of certainty (e.g., body-mind, culture-biology, individual-culture, naturenurture) are considered different and inclusive moments of the same temporal process.

Process-relational meta-theory [Overton, 2013b, 2015] for analysis (two moments) and synthesis (one moment) of development envisages three fundamental principles or multiple moments of a unitary process: (1) The Identity of Opposites, (2) The Opposites of Identity, and (3) The Synthesis of Wholes. First principle frames parts of whole not as mutually exclusive either/ors but as complementary oppositions and differentiated relations. In this way personculture-biology which operate in opposite directions are cast into internally interpenetrated and continuous relations of a unified whole. The opposite of identity moment paves the way for 
scientific scrutinization of development by reasserting Aristotle's principle of contradiction [Lukasiewicz \& Wedin, 1971] leading to relative exclusion (i.e., negation) of unified categories by one another. Consequently, parts of the unified whole differentiate their characteristics and establish their own identity by setting their own boundaries. This in turn gives rise to looking at development from different lines of sight without ontologically divorcing person-culture-biology integrated totality. Third moment, the synthesis of wholes, fuses two moments into an integrative standpoint and resolves bipolarization into an emergent that coordinates two the centrifugal systems [Overton, 2015; Overton \& Ennis, 2006].

From its inception, however, psychology has been concerned with and attentive to Cartesian ontological and psychophysical bifurcation of human consciousness between res extensa (extended substance) and res cogitans (thinking substance). This dualism also is epitomized by severing of the inner, psychical and subjective meaning-saturated system of an individual from the outer, physical and objective world of the extended material reality, branching out psychology into two equipollent camps, namely subjective and objective psychology and exerting a great influence on various aspects of the discipline. The next section proposes that a major source of impetus for Vygotskian CHT was to transcend the objective and subjective impasse in the psychology and human consciousness in particular: that is, to synthesize organicism and contextualism world hypotheses dialectically.

\section{To Subjectivize or to Objectivize Psychology: Is There a Middle Way Out?}

Vygotsky [2012] categorizes the science of psychology into two paradigmatic schools, i.e., the 'natural scientific, materialistic, and objective psychology' versus the 'metaphysical, idealistic, and subjective psychology' [p.87] [see also Teplov, 1957]. Perhaps the most important 
line of inquiry for Vygosky's CHT was the systematic quest for getting to grips with the intractable problem of consciousness without falling prey to neither behavioristic nor idealistic theories of consciousness [Leont'ev and Luria, 1968].Consistent with this general view, Leont'ev and Luria [1956] couch Vygotsky's central premise of arguments in the manner of 'freeing oneself on the one hand from vulgar behaviorism and, on the other hand, from the subjective understanding of mental phenomenon as exclusively internal subjective states that can only be investigated through introspection'(p.6, cited in Wertsch, 1985). According to Vygotsky [1925] '...exclusion of consciousness from the sphere of scientific psychology perpetuates to a certain extent the dualism and spiritualism of the early subjective psychology' [cited in Leont'ev and Luria, 1968, p. 341, italics added].

Subjective psychology or 'science of the spirit' [Vygotsky, 1997, p.110] dematerializes and abstracts mental phenomena (mental existence) and inner experiences (mental processes) from their concrete 'here and now' and objective mediations, individuating human consciousness and scrutinizing it from a first-person (i.e., inner perception or subject-consciousness) perspective. Moreover, the subjective psychology decontextualizes human consciousness from the spatiotemporal and changing exigencies (i.e., the outer physical reality), backgrounding the impact of spatial and diachronic and synchronic scales underpinning and being enacted by human consciousness. Subjective psychology or descriptive psychology as is used interchangeably in Vygotsky's works put itself to the task of trying 'to analyze, classify, and describe the phenomenon of mental life without any appeal to questions of physiology and behavior' [Vygotsky, 1997, p.109].Subjective psychology also assumes directionality to development and, thus, understands the human mind as a purposive, conative, and agential system. 
Subjective psychology, crudely put, sees development as an idealized, design-guided, and introspective phenomenon [Vygotsky, 1997]. It represents an idealistic scientific research program that seeks to measure the essentially interrelated and sequential qualitative changes which are contingent on the totality of an organism and thus invokes formal and final [teleological] causes to explain human development [see also Overton, 2006; Lerner \& Kauffman, 1985; Witherington, 2007]. It should be acknowledged, as well, that final causality is not the same as efficient causality producing anything but is a directional, predispositional, immanent and adaptive factor that makes the connection between a state of affairs and function in a system with its presumed engendering object and process intelligible and tendentially generates order and coherence in a system by continual integration of changes. It must also be noted that finally causality within human-centered phenomena such as human consciousness is primarily endangered from intentionality and purposivity of human being and its intensive quale (an experienced, temporal, and qualitative process) whereas efficient causality is generated from and operative by extensive quantum (an objective, atemporal, and quantitative thing) [KarimiAghdam, 2016b].

The subjective psychology is idealistic, being predicated 'on the basis of the idealistic philosophical assumption of the independence and primordial nature of the spirit on an equal footing with matter' [Vygotsky, 1997, p.110]; bracketing causal influence of the ongoing coconstructed contingencies and the micro-level experiential affordances. The subjective psychology posits that the developmental trajectory of an organism (in our case a human being) evolves teleologically and projectively toward a proleptic and susceptible tendency -i.e., a telos as a contingent, provisional, directional and synthesizing goal- rather than a preordained, monolithic, and deterministic endpoint and design - not yet in existence and actual but a potential 
possibility, thereby grants order and stability to an organism's structural organization and brings directedness out of randomness through the umwelt idiosyncrasies. And this explains in part why Vygotsky [1993] admits that 'essentially, the ultimate character of all psychological acts- their future-oriented directedness-becomes apparent in the most elementary forms of behavior' [p.60].

Hofstadter [1941] functionally - not ontologically - distinguishes between subjective and objective teleology, chalking out subjective teleology to be 'a matter of direct experience, of the experience of purposing, striving, valuing, regulating by norm' and being 'experienced immanently, from a vantage point within the teleological process, by the agent who forms and has purposes, seeks and uses means, and enjoys or suffers outcomes' whilst objective teleology is depicted to be 'a matter of movement or process discovered in subject-matter which is functionally distinct from the agent of discovery qua discoverer and is 'discovered extrinsically, from a vantage point outside the teleological process, by the inquirer after truths about that process'[p. 29]. I should here parenthetically emphasize that organicism is teleological and teleology involved is 'objective' (extrinsic and predetermined) teleology not 'subjective' (i.e., intrinsic and adaptive) teleology [for a clear exposition of objective teleology in relation to purposeful human behavior see, Ackoff \& Emery, 1972]. In a similar vein, change within organicism is teleological and final cause brings order and goal-directedness to changes throughout variegated pathways canalizing, by a dialectic process, all changes unidirectionally to a final end [Ford \& Lerner, 1992]. Such a view is reminiscent of a principle which von Bertalanffy [1968] dubbed it equifinality: ‘... the same final state may be reached from different initial conditions and in different ways' [p. 40]. According to Ayala [1970]:

... [human] actions can be seen to be purposefully or teleologically ordained towards the obtention of the goal. In this sense the concept of teleology can be extended, and has been extended, to describe actions, objects or 
processes which exhibit an orientation towards a certain goal or end-state. No requirement is necessarily implied that the objects or processes tend consciously towards their specific goals, nor that there is any external agent directing the process or the object towards its end-state or goal. In this generic sense, teleological explanations are those explanations where the presence of an object or a process in a system is explained by exhibiting its connection with a specific state or property of the system to whose existence or maintenance the object or process contributes. (p.8)

In this line, Bernstein [1971] while holding that Marx's materialism is a synthesis of traditional materialism and idealism, argues that 'Marx's materialism is essentially teleological, not in the sense that teleology commits us to the fantastic notion that a final cause precedes in time an actual event and somehow directs it, but in the empirical sense of teleology where we want to distinguish goal-directed activity from the mechanical regularity of matter in motion' [pp.42-43].

Vygotsky [1998] argues that it is bound to be misguided 'to consider the development of separate psychological functions and processes only from the formal aspect, in an isolated form, without regard for their direction and independently of the driving force that these psychological mechanisms bring into play'[p.3]. There is also some need for clarification on the distinction between goal-directedness and futuristic purpose across spatial and temporal scales, whether proximate or remote, which directs and harmonizes the present state of affairs into a coherent system and at the same time is regulated and directed by the attentive state of affairs and a univocally deterministic and pre-programmed essence that mechanistically defines, actuates and effectuates an end-point irrespective of the preceding set of paths and processes involved.

Objective psychology or what Vygotsky sometimes termed 'natural scientific psychology' [e.g., Vygotsky, 1997, p. 302; Yaroshevsky, 1968] mechanistically and atomistically weds human consciousness wholesale to discrete and disparate concrete circumstances fetishizing the external idiosyncrasies of time and place. With its passion for wertfreiheit, objective psychology 
looks at human consciousness from a disengaged third-person [object-consciousness] perspective, embeds it within the atomized matrix of actualized social acts and tries, by invoking cause-effect ascriptions, purely objective and quantitative experimental studies and formation of causal hypotheses, to explain a multiplicity of mechanisms and mental states and constituents. In fact, in practicing objective psychology, as Vygotsky [2010, p. 87] says:

we may view mental processes as one among all other phenomena, in close association with them, study them using general scientific methods, strive to represent their workings as an objectively determined chain of causes and effects, identify the laws that govern them, and set as the ultimate goal of scientific knowledge the prediction and mastery of the mechanism of these processes.

From the objective psychology perspective human development is viewed as a probabilistic, contextually susceptible, contingent and inter-organism phenomenon. Building upon an atomistic and reductionist world-outlook, objective psychology is epitomized by its exclusive focus on discrete and situated quantitative changes in real-time characterized by the immediacy of 'hereand-now' contexts. These quantitative and essentially homogeneous changes are contingent upon immediate context, consequently giving 'disorder' and 'fluidity' to an organism's development. Objective psychology, Vygotsky [1997] argues, aims at 'a complete explanation of correlative activity without mind and then mind is made into a superfluous, unnecessary phenomenon' [p.45]. Drawing upon efficient and material causalities and drifting formal and final causalities to the periphery, objective psychology purports to account for the changes constituted by mutual conditioning between an organism and its changing context [i.e., adaptation]. An organism can take and reconfigure alternative future developmental trajectories over time solely based on the concrete actions and analytically well-determined elements which 
are encompassed within empirical contexts. But two points should be re-emphasized here: first, as noted above organicism and contextualism have a propensity to be colligated with mechanism bringing a degree of versatility to identification and adumbration of the fundamental premises which are translated, either explicitly or implicitly, into developmental theories. Second, organicism and contextualism have been subject to capricious interpretations primarily in terms of invoking different levels of explanation (i.e., efficient, material, formal, final). In view of these points, it does seem drawing a conspicuous parallel between subjective psychology and 'expurgated organicism', on the one hand, and objective psychology and 'expurgated contextualism' on the other hand thus is injudicious [see also Morris, 1993, 1997].

I argue that Vygotskian dialectical cultural-historical theory (CHT) bridges the fundamental and apparently irresoluble dichotomy between the subjective and objective psychological inquiries of human consciousness or in Vygotsky's [1979] words between dualistic psychology of 'mind (i.e., psyche) without behavior' and psychology of 'behavior without mind'. Vygotskian CHT endeavors to lay an integrative vestibule to a unified psychology which describes and explains human consciousness and mental states as actualized in, and for the sake of, the purposive and intentional praxis. Praxis or practical social activity [Leont'ev, 1981; Luria, 1971; Kilminster, 1979] which epitomizes 'humans making history through action, human activity as the process, or the reality, of history' [Glassman 2000, p.11] and is imbued with intentionality humanizes the socio-physical ambients and at the same time is transformed by sociocultural and mind-independent but human-generated contingencies that are created, realized and revealed historically. Praxis, within the framework of this view, is a psycho-socially fashioned human-oriented purposive, emergent and dynamic activity that is materialized in order to come to terms with the outer reality primarily mediated with a dialogical and collective 
communal social practices and at the same time is actualized to appropriate, control and form the social reality and human subjectivity over time [e.g., see Stetsenko, 2009; Ratner, 2016]. Fedoseyev for example, says that, 'the interaction of the subject and object in the process of practical activity' comprises the steadfast core of human cognition [Fedoseyev, 1977, p.15]

According to Leont'ev and Luria [1968] Vygotsky 'rightly rejects simplified attempts to infer man's consciousness directly from his practical activity. But in his own psychological theory of consciousness, he [Vygotsky] illegitimately deduced the purely cognitive relationship of man to the world from man's practical activities and relations' [p.355].Vygotsky [1997] provides a strong defense of this view when he concludes that 'only dialectical psychology, by claiming that the subject matter of psychology is the psycho-physiological unitary integral phenomenon' [p.120]. According to Valsiner \& van der Veer [2000] broadly conceived, Vygotskian CHT seeks to sanction 'an account of phylogeny and ontogeny which stresses both continuity in development (evolution) and the emergence of qualitative changes (revolution) [p. 349]'. In the following section the general outlines of Vygotsky's CHT are examined through the lens of the Pepperian RMT.

\section{Vygotskian Cultural-Historical Theory: A Dialectical Synthesis of Contextualism and Organicism World Hypotheses}

Lev Vygotsky, a dialectical psychologist [Van Der Veer \& Valsiner, 1994] sought to bring a Hegelian and Marxian dialectic to bear on his psychology [Davydov \& Radzikhovskii, 1985; Dixon \& Lerner, 1992; Tolman, 1983]. Vygotskian CHT addresses '...the complex relations between the biological, organic basis of interests and the complex process of the development of their higher formation...' [Vygotsky, 1998, p.11] where development, as Valsiner [1998] 
succinctly states, entails '.. differentiation of psychological functions (from 'lower' to 'higher' kinds, distinguished by the semiotic mediation of volitional processes)' [p. 200]. More specifically, Vygotsky's CHT [1978, 1986, 1997] is a representative example of a research framework which endeavors to scrutinize the continuous process of 'becoming' [i.e., processual flux] of human development, and to interfuse two world hypotheses (i.e., organicism and contextualism) by drawing upon a dialectical logic.

Dialectical psychology of human development definitive of Vygotskian CHT homes in on quadripartite-faceted and interdigitated dimensions simultaneously, namely (1) inner-biological (2) individual-psychological (3) cultural-sociological and (4) outer-physical [Riegel, 1975, 1976, 1978, 1979]. Without being overemphatic, however, I think the theoretical chasm between the individual and the social cannot be spanned unless all these four facets of human development are coalesced into a time-dependent unity bound by reciprocal relations and mutual imbrications across polychronic and polyvalent levels of a developmental system. In Kojève's words [1969] 'the historical movement arises from the Future and passes through the Past in order to realize itself in the Present or as temporal Present' [italics in the original, p. 136]. The Vygotskian CHT holds that the genetic roots of the human higher-order functions and processes emerge out of the interrelated multiplicative interaction among four nested and temporal genetic systems, viz. phylogenesis, culturogenesis, ontogenesis, and microgenesis that are inseverable ontologically [Vygotsky, 1987; Cole \& Hatano, 2007].

Vygotskian CHT 'historicizes human development and consciousness, intending to investigate the processual trajectory of human development evolving dynamically with both short and long time-scales that are experienced subjectively and simultaneously' [KarimiAghdam, 2016b, p.92]. Phylogenesis emerges at evolutionary timescale, culturogenesis emerges 
at historical timescale, ontogenesis emerges at idiographic timescale and microgenesis emerges at real timescale [see also Cole \& Engeström, 1993]. It should be emphasized that 'different progressions within one particular and between two different dimensions are not always coordinated and synchronized' [Riegel, 1979, p.8] but are nevertheless constitutive and coevolving and 'development results from the synchronization of any two and indirectly of all of these progressions' [ibid. p.13]. If read in the light of Pepper's categorization of metaphysics it could be argued that that Vygotsky's [1978, 1986] cultural-historical theory of the human development integrates two dialectically contradictory world hypotheses namely, organicism and contextualism, thereby explicating the dynamic (time-bound) and holistic nature of the emergence of human consciousness.

Vygotskian CHT's holistic conception of human consciousness, however, is not a weakness or infringement on Pepper's [1942] caveat against eclecticism for at least three reasons. First, Pepper's RMT is a descriptive rather than a prescriptive theory about the origin and development of substantive philosophical doctrines [Pepper, 1973]. Therefore, it would be untenable to affirm that Vygotskian CHT could not achieve an embracing and defensible integration of organicism and contextualism world hypotheses since Pepper [1942] has cautioned about the problems of combing world hypotheses to occasion a more coherent and comprehensive world hypothesis. Second, Vygotskian CHT has conjoined two world hypotheses so as to eschew atomizing human consciousness into its discrete and piecemeal constituent parts-aligning with objective psychology- or idealizing human consciousness into a reified mental and intellectual entity aligning with subjective psychology-but to understand why and how consciousness - 'a critical moment in the transformation of man from thing to self-activity' [Jacoby, 1970, p. 25] - emerges in and over time. 
As Rubinstein [1957] succinctly states 'man is both a product of the development of nature and the subject of history... [therefore] psychology...dealing with the nature of man which is the product of history, has special connections with sciences that deal with nature ... and with sociohistorical sciences' [p. 267, italics in the original]. Third, Pepper [1942] himself contends that organicism and contextualism are closely interlacing world hypotheses. Relatedly, when traced back to their bedrock ontological assumptions and postulates, organicism and contextualism world hypotheses are potentially complementary and reconcilable. Importantly, Pepper [1942] holds that 'contextualism and organicism are so nearly allied that they may almost be called the same theory, the one with a dispersive, the other with an integrative plan... [that] seem almost to shade into one another' [p.147]. It is simply an overstatement of the case to say that Vygotskian CHT needs an epistemological hoist to build his relational world view and show, in effect, how subjective and objective can be fused and approached.

One of the most comprehensive philosophical frameworks for documenting integrating world views is the Hegelian dialectic [Ilyenkov, 1977; Taylor, 1975]. Dialectic logic is based on 'an empirical descriptive theory' [Popper, 1940], that strives to transcend a priori synthesis of world views. Afanasyev [1980], while holding that the most fundamental question to be answered by philosophy is to spell out the nexus between 'being' and 'consciousness', defines dialectical materialism as '...a science which on the basis of a materialist solution of the fundamental question of philosophy discloses the more general, dialectical laws of the development of the material world and the ways for its cognition and revolutionary transformation [p.22].'

It is claimed here that Vygotskian CHT, by drawing upon a dialectic expansionary triad [i.e., thesis, antithesis and synthesis] stands against an a priori dismissal of synthesis of different 
world hypotheses. Specifically, contra to Rogoff's [1982] conjecture that Vygotsky's CHT falls into the purview of contextual event approach or, in Pepper's categorization into the contextualism world hypothesis, I argue that the CHT perspective of human development selfconsciously draws upon dialectical and relational epistemology to address the [apparent] clash between contextualist [i.e., the social] and organismic [i.e., the individual] aspects of human development and examine, within a unified ontological umbrella, human development and consciousness [see also Bidell, 1988; Ratner, 1991; Cole \& Gajdamaschko, 2010]. Stetsenko [2008] implicitly vindicates the view that Vygotsky's CHT is predicated on wedding contexualism and organicism world hypotheses, conjugating 'history' and 'biology' as two contributing but internally relational and dynamic factors to human development:

...much of Vygotsky's efforts can be read as an attempt to conceptualize human development in terms of an organism- environment nexus in which the two continuously determine each other so that neither one can be conceived independently. In fact, one of Vygotsky's core achievements was that he substituted for the fixed, preformist views on development the notion that development exists in flux and constant change, with fluid and ever-changing, open-ended dynamical processes linking organisms and their environments. (p.475)

Likewise, Novikoff [1945b] holds that 'It is the continuous interplay between biological and cultural influences which determines an individual's personality and behavior' [p.406].

The main axiomatic calculi of the dialectical synthesis of the social and the individual in CHT can be enumerated as contradiction, change, praxis (i.e., human willed and contingent practical activity in time), totality (i.e., wholeness) [see also Adoratsky, 1934; Baxter \& Montgomery, 1996; Ollman, 1976], interpenetration, the structure of dynamic process, integrated 
levels and historicity [Levins, 1998]. It is the dynamic interaction of the stability and flow in the lower psychobiological processes and dynamics in the higher intellectualized and mediated psychological functions that provides a causal impetus for both contingently teleological and probabilistically indeterminate end states in human development. Vygotsky [1960] maintains that 'the process of the historical development of human behavior and the process of biological evolution do not coincide; one is not a continuation of the other. Rather, each of these processes is governed by its own laws' [p.71, italics added cited in Cole \& Engeström, 1993].

This conceptual thrust of CHT is succinctly elucidated by Vygotsky [1978] where he argues that '...child development is a complex dialectical process characterized by periodicity, unevenness in the development of different functions, metamorphosis or qualitative transformation of one form into another, intertwining of external and internal factors and adaptive processes which overcome impediments.... [p.73, italics added]. Vygotsky [1989] trades on two cognate notions of history in his cultural-historical psychology, namely dialectical histories (i.e., biophysical evolution) and historical materialism (i.e., human history) to conclude that the uniqueness of human mind stems from synthesizing two kinds of histories into a unified rather than uniform (i.e., homogeneous) totality [pp. 54-55].

This interpretation is reinforced by the fact that for a dialectical psychologist developmental change as a process [Overton \& Reese, 1981] is based on three laws: (1) the struggle of opposites in which the cultural-historical and the natural-biological are dialectically synthesized, (2) the transformation of quantitative change into qualitative development (i.e., emergence) and (3) the negation of negations which is an unceasing and recursive process of a spiral replacement of old with new [Wozniak, 1975; Adoratsky, 1934]. 
In fact, as these laws demonstrate dialectic is an illustration of the inexorable process wherein spontaneously emergent systemic patterns- and in case of the cultural-historical theory higher level-functions and consciousness- are objectified into qualitatively novel properties. Higher-level functions, and by extension our conceptions of the human mind, are neither predictable from, nor reducible to their constitutive lower-level entities or functions. These higher-level functions develop 'according to completely special laws and [are] subject to completely different patterns' [Vygotsky, 1998; p. 34]. Therefore, as intimated above, Vygotsky [1978] conceives of development as a complex, non-linear, emergent, dynamic and relational system or what he refers 'changes in the type of the development itself' [Vygotsky \& Luria, 1993, p.37, italics in original cited in Wertsch, 1994].

It is worth noting that the organicism world hypothesis, considering the dialectic to be part of its category [Overton, 1984] holds that sensible experiential fragments because of their interconnection and internal drive to co-evolve are constituted by contradictory aspects. Spontaneous and progressive self-organizational processes give rise to emergent organic wholes. These newly organized systems transcend the preceding contradictions without obliterating their constitutive elements [Pepper, 1942].

Vygotsky also draws upon a Hegelian system of dialectical logic while discussing the concept of mediation [Kozulin, 1990]. Mediation - a process by which the subject and object are interconnected with relations of mutual presupposition- is crucial to dialectical thinking and overcoming the internal and the external dichotomy [for a nuanced discussion about (cultural) mediation, see Arievitch,\& Stetsenko, 2014;O'Connor, 1999]. It should be emphasized, however, that 'the subject is not simply consciousness, it is a real and acting person' and 'the object is not simply objective reality, but that part of it which has become the target of the practical or 
cognitive activity of the subject' [Lektorsky, 1977, p.101]. The dialectical mediation of the subjective experience and objective reality qua forming practical activity changes the relationality of consciousness and its object but also pupates the nature of both. Human consciousness endowed with purpositivity and intentionality revivifies material socio-historically mediated and molded semiotic signs, tools, symbols and artifacts and correspondently changes the ideational nature of the material while simultaneously becoming object to its subjectivity. Human consciousness has no substantive and subsistent existence by itself and in itself; On the contrary, we have mediated cognizance of consciousness by objective patterning and constant actualization of its intellectual ideations that assume the form of about-directed practical activity- including speeching activity and manual activity- which is enmeshed with, and sedimented in discursive, collective, historical and encultured artifacts (both ideational and physical) [for a discussion of speeching activity, see Karimi-Aghdam, Dufva \& Lähteenmäki, forthcoming; Roth, 2016].

Vygotsky's conception of 'mediated act' [Engeström, 1987; Davydov \& Radzikhovskii, 1985; Vygotsky, 1981b] is meant primarily to account for higher psychological and specifically human processes which are not derivatives of immediate presentative cognition that 'presupposes direct reaction to the task set before the organism (which can be expressed with the simple S-R formula)' [Vygotsky, 1978, p. 39]. Contrariwise, mediated act as propounded by Vygotskian CHT presupposes on the one hand the generativity of sociohistoricallyaccommodated signs and tools and on the other hand the individuation and transformation of mediated representative cognition. Artifacts including functionally interconnected ideational signs and physical tools- both medium and product of historical phylogenesis and phylogenetic history- indirectly 'transfer[s] the psychological operation to higher and qualitatively new forms 
and permits humans, by the aid of extrinsic stimuli, to control their behavior from the outside' [Vygotsky, 1978, p. 40].

Dialectical logic, considered by Hegel as 'the form ... of thought that included the process both of elucidating [the inner] contradictions and of concretely resolving them...'[Ilyenkov, 1977, p.190] gives Vygotsky a handle for what Wertsch [1991a] terms the genetic [i.e., developmental] analysis of human mental functioning. This 'experimental-developmental' method of analysis of higher psychological functions is based on three principles (1) analyzing process of behavior and consciousness development, (2) genotypic explanation of actual dynamic relations and (3) dynamic analysis of fossilized forms of behavior [Vygotsky 1978, pp. 60-64]. For Vygotsky [1978] dialectic is laced with psychological strands. This is more pronounced when he writes:

The search for method becomes one of the most important problems of the entire enterprise of understanding the uniquely human forms of psychological activity. In this case, the method is simultaneously prerequisite and product, the tool and the result of the study. (p. 65; italics added)

Human consciousness is not bounded by, but actively realized through and constructed by the material social milieu. Therefore, as a contingent and emergent whole human consciousness is neither reducible to nor predictable a priori from the constitutive emergent social purposive activities or evolutionary/biophysical structures and processes. Furthermore, the agentive orienting power of human being qua subjective-activity-in-the-objective-world refashions the world from which its very agency was originally and socially derived and in turn is reacted back and contributed by its own imprints. In doing so the process of development obviates consideration of the subject's consciousness as a passive receptacle on which alien objective 
reality is imprinted unmediated. In that light it is not surprising that Vygotsky [1978, p.46], for example, when discussing the emergent nature of sign operations, affords support to this interpretation:

... sign-using activity in children is neither simply invented nor passed down by adults; rather it arises from something that is originally not a sign operation and becomes one only after a series of qualitative transformations. Each of these transformations provides the conditions for the next stage and is itself conditioned by the preceding one; thus, transformations are linked like stages of a single process, and are historical in nature... [the higher psychological functions] are subject to the fundamental laws of development... as the outcome of the same dialectical process, not as something introduced from without or from within. (emphasis in the original)

It should be noted that here Vygotsky underscores the fact that higher psychological functions cannot be studied by invoking physiological or morphogenetic methodology and, by the same token, by reducing higher functions to conditioned elementary reflexes, habituated responses and somatic evocations of human nervous system by the external stimuli without taking on board the inner experience of human being (from without). Nor is it tenable, Vygotsky emphasizes, to investigate human socioculturally-mediated behavior (i.e., higher psychological functions) by solely drawing upon the nexus of immediate and self-contained data of consciousness (a direct knowing) that a living human being experiences in his/her own inner consciousness short of paying attention to the corporeal and physiological dimension [from within]. Not only is it the case that higher level functions are generated from a synthesis of biological [ontogenetic and phylogenetic] and psychological (microgenetic and culturohistorical) dimensions across various timescales but also human beings primarily come to terms with 
themselves and the world in and through practical activities that embody the objectifications of their inner subjectifications and unremittingly interpenetrate states of affairs of the outer reality and states of mind of the inner reality [see also, Ilyenkov, 2012]. This reasoning also seems in line with Leont'ev's Marxist stance, recognizing the emergence of consciousness 'as a result of the development of the agent's activity in the object world' [cited in Wertsch, 1981; p. 10]. On the same score, Rubinstein [1957] argues that

A psychic process, a psychic activity, is always a link between the individual and the world. In psychic activity something always occurs which produces a reflection of objective reality, i.e. its image. An image in itself, apart from a psychic process or activity, is not, and cannot be, a subject for psychological investigation. An image cannot exist apart from a process, though under certain conditions it appears to the subject to do so because the process itself, in which the image is formed, is not perceived by the subject....Psychic processes and psychic activity must, therefore, be regarded as one of the forms of connection between the subject and the objective world. (pp. 275-276)

The unity of organicism and contextualism world hypotheses is salvaged in CHT, from the standpoint of Hegelian dialectical logic which 'transcends static assertions' and gives content to identity. Seen through the prism of dialectical logic, Vygotsky [1978] considers phenomenal functions [i.e., functions that are perceptible directly through immediate experience] neither functionally identical nor necessarily qualitatively expandable, to noumenal functions (i.e., functions that are apprehended by intellectual intuition rather than by the senses). This does not repudiate the fact that when a quantitative change reaches a critical point, a qualitative transformation occurs (i.e., emergence) [Ablowitz, 1939; Ollman, 1976]. For Vygotskian CHT elementary functions such as mechanical memory, perception, and involuntary attention are 
essential prerequisites for, but categorically distinctive from, higher order mental functions such as intentional memory, voluntary attention and logical thought in human consciousness [e.g., see Moll, 1994; Rogoff, 1988, 1992]. As Luria [1981] points out 'the ability to transcend the bounds of immediate concrete experience (i.e., unreflecting, direct, unmediated experience processed with a minimum of cognitive effort) is a fundamental feature of human consciousness' [p.19].

Therefore, higher-level functions cannot emerge without the elementary functions, which preceded them. As Vygotsky [1999] writes:

The history of development of each of the higher mental functions is not the direct continuation and further improvement of the corresponding elementary functions, but undergoes a radical change in development and a subsequent movement of the process to a completely new plane; each higher mental function is, thus, a specific neoformation.... Higher mental functions are not built up as a second story over elementary processes, but are new psychological systems that include a complex merging of elementary functions that will be included in the new system, and themselves begin to act according to new laws; each higher mental function is, thus, a unit of a higher order determined basically by a unique combination of a series of more elementary functions in the new whole. (pp. 42-43)

Higher mental functions, however, are emergent properties or in Vygotsky's words 'neoformations' which are causally originated by, and in essence are derived from, internally relational [see Ollman, 1976] elementary functions but are qualitatively different from them and assume novel qualities and enjoy a causal autonomy over and above the lower-level functions. Put another way, higher mental functions are emergent functions sui generis at a different and higher-level of organization. Higher-order functions arise and have properties not possessed by 
lower-order functions. A set of constituent lower-level functions or processes and the timevarying relationships among them bring about functions at higher-level of the multileveled organization of human development. Correspondingly with mutually dependent functions and relations, therefore, higher-order functions may not be accounted for in terms of lower-level functions at another level albeit they are causally dependent on configuration of lower-level functions.

If the properties of higher-level functions were reducible wholesale in terms of features and causal potency constitutive of that level to properties and causal power of the functions of preceding level, then emergence of genuinely novel and de facto existence of higher levels in a hierarchical organization of human development discussed above would be contradictory. Every level of human development conserves the preceding levels and this conservation does not imply that mechanisms, processes, structures, functions and causal influence of downward-levels or upward-levels remain unchanged or become actually obliterated. One level is added onto, and reciprocally and multidirectionally interacts with, the preceding ones, and thus, when the next level emerges, it is added onto and interacts causally with all the other antecedent ones plus the level that emerged proximately yielding an open-systemized totality with quantitative and qualitative dimensions. This view is further sanctioned implicitly by Vygotsky [1929] where he entertains the idea that

...cultural development does not create anything over and above that which potentially exists in the natural development in the child's behaviour. Culture, generally speaking, does not produce anything new apart from that which is given by nature. But it transforms nature to suit the ends of man. (p.418) 
From Vygotskian CHT vantage point the difference between an elementary function and a higher-order function is not their quantitative complicacy but their qualitative properties and organized complexity [e.g., see Vygotsky \& Luria, 1994]. Likewise, mere accumulative aggregation of the elementary functions does not necessarily lead to higher-level functions even though they are adjuvant to emergence of higher-level functions. On the contrary, each higherlevel function may emerge through developmentally revolutionary process engendered by the continual internal interactions among lower-level functions without any exogenously exerted force over different temporalities. Higher-level functions are irreducible to lower-level functions owing to the fact that they possess novel properties and unpredictable contrivances which their respective lower-level functions lack [Vygotsky, 1987].

These assertions, from a CHT standpoint, seem to be tenable as Vygotsky [1998] maintains that higher mental functions '... are constructed according to the pattern of development of new complex combinations of elementary functions through the development of complex syntheses' [p. 84; Italics added]. Ontologically oriented dialectic, like the organicism world hypothesis, regards the reality and its ultimate constituents as an infinitely dynamic process and a flowing of actual movement and development which are borne out of the transcendence of internal contradiction of Being and Nothingness synchronously [Ilyenkov, 1977; Lefebvre, 1968]. Vygotsky [1978, 1986], correspondingly, champions the process metaphysics [Bickhard, 2008; Rescher, 1996; Overton, 2015] when he traces the genesis of higher psychological functions of the human mind back to the mediational history of tools/artifacts and collectively-fashioned semiotic sign systems between mutually opposing and interconnected components. That is, between an active organism and social milieu in which speeching and practical activity converge into a whole ensemble [Cole \& Wertsch, 1996]. The relational mode of thinking about human 
development and human consciousness in particular which Rubinstein terms 'constitutive relationism', according to Riegel [1978, pp.13-14]

emphasized the material basis from which relations originate and through which they generate double systems of interactions, namely between psychological and outer cultural-sociological conditions [representing the historical dialectics of Soviet psychology] and between psychological and inner biological conditions [ representing the material dialectics of Soviet psychology].

The very process of internalization of the historical, social and institutional dimensions of material reality via cultural-historical semiotic tools and signs as material mediators, of which speech is the most important, into intra-psychological higher mental functions is 'the truth' of consciousness and thought in CHT. In Overton's [1998] words 'the sociocultural interpersonal process has been the Vygotskian focus; yet, Vygotsky's writings demonstrate a significant interest in 'intrapsychic dynamic organizations of the person' [p.142, italics added].

One line of reasoning for this conclusion is that contradiction, 'the concrete unity of mutually exclusive opposites' [Ilyenkov, 1977], between polar co-ordinates and antinomies in CHT (e.g., individual vs. society; learning vs. development; zone of proximal development vs. zone of actual development; higher order functions vs. lower order functions; speech vs. action; the ideal vs. the material; the physical vs. the cultural-historical; fluent motion vs. static permanence; subject vs. object; being vs. becoming; inner vs. outer; genesis vs. analysis; intraindividual vs. inter-individual; internal vs. external; evolutionary change vs. revolutionary change; speech vs. thought; psychic vs. material; biology vs. culture) are taken as the driving impetus for the change and flow [e.g. see Cole \& Wertsch, 1996]. The interpenetration of these opposites effects the non-iterative and non-stationary processes of qualitative changes that are 
societal in origin and time-locked in nature. The progressive processes through which qualitative changes [i.e., emergent properties] in human development as an eventual coherent whole and nexus are generated are neither repetitious nor static but are dynamic, societal, helical and timedependent.

One conspicuous lacuna in most extant work in Vygotskyian scholarship is the negligence of the causal influence of the higher mental functions on inter-psychological plane via multi-modal sensory-motor activity systems of which language is its most salient semiotic and temporally structured linchpin. For example, internalizing linguistic functions through social interactions effects the ways a child solves non-linguistic problems. As such, the bi-relational synthesis of the intra-psychological and inter-psychological planes (i.e., thought and situated empirical activity) of human consciousness highlights cardinal importance of praxis as one of the main tenets of CHT dialectic. Zaporozhets [2003], for example, taking the lead from A.N. Leontiev's discussion holds that 'in psychology, external, material, practical activity should always be considered in its relation to mental reflection' [p. 49] Interestingly, however, the notion of goal and goaldirectedness is emphasized in Vygotskian CHT and the Soviet psychology in general which conceivably has its roots in Marx and Engels arguments that regard purposive and conscious goal-seeking practical activity a uniquely human trait [Wertsch, 1981; Engeström, Miettinen, \& Punamäki, 1999].

CHT regards human development as an unwinding and capillary trajectory. Human development progresses through intentional human agency as temporal and situated activity-forothers. Therefore, the argument here is that $\mathrm{CHT}$ resolves controversies, concerning the priority of either the social or the cognitive, and demonstrates the synthesis of organicism and contextualism world hypotheses. More to the point, CHT may be particularized from an 
organismic perspective as a 'teleological-historical' and 'active-organismic' psychology, but one that is also in conformity with contextualism world hypothesis which considers 'the activities of the individual... as being in dynamic interaction with the activities of the environment' [Dixon \& Lerner, 1984, p.25].

For Vygotsky consciousness is primordially affine to the changing concrete and objective. By the same token the mutable concrete and objective are hinged on the human consciousness using experiential (spatiotemporal) activity as a welding point. From the CHT standpoint human consciousness is always about the world while the world is defined by human consciousness: their relationship is in essence co-constitutive rather than contingent and epiphenomenal. In Vygotsky and Luria's [1994] words, 'the whole dialectic of the organism' is constituted by two tendencies 'conservative-biological' and 'progressive-sociological' [p.16].Vygotsky [1978, p.56] maintains that 'development... proceeds ... not in a circle but in a spiral, passing through the same point at each new revolution while advancing to a higher level' [italics added].This argument reinforces Vygotsky's contention that transformation of external actions, psychological tools and signs as well as actual social relations in child's cultural development appears two times: first on the social plane and then on individual plane [Kozulin, 1986; Vygotsky, 1978, 1986]. As a result some externally developing functions, such as the psychophysiological functions, remain isomorphic to the context-conditioned representations and preserve their system of identity in terms of contents and forms. Other more internally developing functions acquire novel qualities. This observation resonates with Vygotsky's [1998] thesis that higher mental functions are

the product of the historical development of humanity'- and not merely an accrual nor continuation of elementary functions but... together with the development of content, there is a development of 
forms of thinking and those higher, historically developed forms and abilities of activity whose development is requisite condition for growing into a culture. (p.34)

By historicizing the development of higher mental functions Vygotsky [1998] accounts for revolutionary emergences (i.e., transformative and qualitative changes). Nonetheless, Vygotsky's [1978] observes that 'revolution and evolution as two forms of development ... are mutually related and mutually presuppose each other.' [p.73, italics added]. According to CHT the uniquely human functions are instantiated and made operative by historically and culturally emergent patterns that are appropriated by humans and mediated mainly through situated verbal activities, and socially (i.e., historically and culturally) constructed and embedded signs and artifacts.

To explain the genesis of human higher functions, tracing back the trajectory of higher functions ex post facto is futile and unpalatable inasmuch as human higher-level functions are global emergent properties of human consciousness and are not merely an aggregative mélange of elementary functions of human development (i.e., organicism world hypothesis). As Vygotsky [1981b] phrases it, 'all higher functions are not developed in biology and not in the history of pure phylogenesis. Rather...all higher mental functions are internalized social relationships' [p.164]. The investigation of trajectory and temporal fluidity of higher mental functions to pinpoint the transformative moments and timescales in the unified human development process is of paramount importance from a CHT standpoint [e.g., see also Cole \& Engeström, 1993]. According to CHT, there is no higher-order function without lower-level elementary function. This point is echoed in the following quote from Leont'ev: '...if we removed human activity from the system of social relationships and social life, it would not exist....the human 
individual's activity is a system in the system of social relations. It does not exist without these relations.' [Leont'ev, 1981, pp. 46-47]

There may also be elementary functions that do not necessarily involve any higher-level functions. Therefore, both qualitative and quantitative changes should be accounted for from CHT vantage point to depict a balanced picture of human development. It is the unity of continuity of quantitative changes and discontinuity of qualitative transformations of interpersonal processes ad infinitum that jointly engenders the internalization of psychological tools and signs and consequently brings about human consciousness.

On close scrutiny, it becomes evident that Vygotsky [1998] disapproves the standpoints which consider human development as a gradual accumulation and evolutionary addition of separate accretions in biophysical plane. Interestingly, however, Vygotsky [1978] considers erratic changes and leaps in the process of child development as mutually compatible and reciprocally constitutive with the continuous evolutionary progression; hence functionally they are inseparable from one another. For Vygotsky [1978]

maturation per se is the secondary factor in the development of the most complex, unique forms of human behavior. The development of these behaviors is characterized by complicated, qualitative transformations of one form of behavior into another [or, as Hegel would phrase it, a transformation of quantity into quality]. (p.19, italics added)

It may be concluded that Vygotskian CHT accords a central role to a dialectical interplay of the higher level and lower level functions in the emergence of human consciousness.

Owing to the fact that the synthesis in the dialectical triad is more than the sum of thesis and antithesis, the totality of human consciousness, from a CHT standpoint, is an emergent system 
which involves all lower level functions and higher-level contemplative functions but possesses properties and qualities which cannot be explained exclusively nor explicated fully in terms of properties of one or the other. As Bakhurst [1991, pp.67-68], explains:

He [Vygotsky] argues that, if the mind is conceived as a totality of evolving interfunctionally related capacities, then its nature can only be captured by a historical theory.... Vygotsky's functionalism grounds his claim that the mature psychological functions are irreducible to their primitive antecedents. On Vygotsky's account, the development of each psychological capacity is mediated by developments in the other capacities to which it has an interfunctionally graded relevance. Thus, the development of any capacity represents not a linear process of steady growth but a 'dialectical' series of abrupt qualitative transformations precipitated by changes in other capacities. These qualitative changes [or 'leaps'] between stages in the development of a function mean that its nature cannot be reduced to the form in which it first appears (Vygotsky 1978, p. 57).

Developmental systems such as human consciousness change with time and some changes are irreversible. The qualitative and subjective higher-level human functions are not really a static and cumulative aggregate of wholly independent lower-level natural-biological changes but supervene upon them. For instance Wertsch [1985] holds that for Vygotsky the natural line of development provides necessary but uncomfortably insufficient conditions for the development of a cultural line of human consciousness.

By virtue of their qualities and properties, emergent array of higher-level functions engender changes on the relational status quo of the human developmental system. More importantly, selfstructuration of lower-level functions and their interpenetrative and non-additive interactions 
may engender higher-level functions without causation ab extra (i.e., causality which is foreign to human developmental system).

Valsiner and van der Veer [2014] share a similar conviction by holding that 'the actual dialectical synthesis at crisis periods (catastrophic breakthroughs in the ontogenetic development) leads to the reorganization of the structure of 'central' and 'adjacent' psychological functions in ways that give rise to novel (qualitatively genuine) functions on the basis of loss and reorganization of the previous ones' [p.158]. Vygotsky [1997a] invoking the notion of 'psychological system' (i.e., relational organization of the evolving and ever-changing sets of relations between functions) asserts that the lower-level and higher-level functions as a structured, hierarchically nested, interconnected and dynamic whole emerge from the interaction between internally related functions, along with the reconfiguration of their interrelations [see also Zavershneva 2014]. Therefore, the functioning and reconfiguration of the psychological systems furthers the development of human consciousness. Further, Vygotsky [1998] captures this point when he writes:

In the process of development, all of these functions [attention, memory, perception, will, and thinking] form a complex hierarchic system where the central or leading function is the development of thinking, the function of forming concepts. All the other functions enter into the complex synthesis with this new formation; they are intellectualized and restructured on the basis of thinking in concepts. (p. 85; Italics added)

The foregoing reflections suggest the conclusion that the very dyadic mechanism of the emergence of higher functions are uniquely-human in terms of their qualities. Moreover, they are mediated via socially-historically constructed signs and tools scaling up certain of the lower- 
level functions but do not annihilate them. The emergence of semiotic sign-conditioned functions whereby the external functions morph into and are mediated by internal functions and ideas, enfolds all lower functions of human development. It should be noted that Vygotsky [1978], possibly so as to signify the notion of 'supervenience', uses the terms 'involution' or 'turning inward'.

Vygotsky [1978] by using the term involution implies that emergence of the ensemble of higher level functions in the developmental trajectory of human consciousness, essentially a temporally embedded process across different timescales, supervenes upon and encompasses all the biological and elementary functions without superseding them [for a detailed discussion of CHT and emergentism, see Sawyer, 2002 a \& b]. Even though Vygotsky never elaborated on his concept of 'involution' it illuminates the bidirectional causal influence between higher-order and lower-level functions of human development.

Surface manifestations and developmental behaviors can have different 'essential causes'. Conversely, similar causes may manifest different characteristics and features in human consciousness. From a CHT perspective, that which is empirically observable does not necessarily reflect the essential real of human consciousness. I observe with Wertsch [1991b] that for Vygotsky consciousness and higher-level human functions have their origins in external material world of society and are continually in motion but they are not 'carbon copies' of a physical world which is socio-historically constructed.

This argument points in the same direction as Vygotsky and Luria [1994] chart out:

... the physiological higher functions form a physiological system, integral in its generic character, although manifold in composition, built on foundations entirely different from those of the elementary psychological functions. The factors uniting the whole system [i.e., physiological 
system]...is the common origin of their structure and function.... in their phylogenesis they are the product not of biological evolution, but of the historical development of behavior, while in ontogenesis they have also a special social history. (p.137, italics in original)

In summary, Vygotskian CHT (a) subscribes to the non-reductive materialism, that is, it holds that human consciousness is materially heteronomous and predicated upon the physical. But human consciousness is an emergent phenomenon with culturally mediated higher-order properties, patterns and functions that are genuinely and qualitatively novel and thereby irreducible to the properties of its material constituent parts and without being a transcript of the physical. Therefore, human consciousness is considered to be ontologically autonomous and real; (b) assumes the process-based nature and incessant fluent movement and constant change of the material Reality with a capital $\mathrm{R}$ as its ontological (i.e., metaphysical) standpoint, (c) draws upon the dialectical method to explicate dynamic, mediated, complex, interconnected and emergent nature of human consciousness and finally (d) strives to overcome the longstanding bifurcation between the social and cognitive dimensions of human development by adopting a monistic and relational ontology which synthesizes some axioms of, to use Pepperian RMT terminology, contextualism and organicism world hypotheses.

\section{Conclusion}

The central thesis of this article was to unearth at least insofar as possible some of the underlying assumptions and axioms which underpin CHT by drawing upon Pepperian RMT and to demonstrate how dialectical logic is profitably employed therein to synthesize seemingly opposed positions of the subjective and the objective psychologies. Pepper's [1942] root 
metaphor theory was introduced to contextualize and to trace out systematically the purported 'grand' world hypotheses [i.e., philosophical systems] and the ancillary axioms upon which Vygotskian CHT is premised. Pepper [1942] has encapsulated in a systematic, contrastive and precise categorization the most influential schools of thought that subtend scientific theories in one way or another. This paper argues Vygotskian CHT circumvents the vicious circle of proffering either an individual-only (i.e., subjective psychology or organicism world hypothesis) or a social-only (i.e., objective psychology or contextualism world hypothesis) account of human development. It does this by invoking a construct of human activity where a fusion of these seemingly stand-alone world hypotheses is realized. Moreover, it was stressed that Vygotsky subscribes to a relational epistemology (i.e., a dialectic method) and a monistic ontology (i.e., holding that the ultimate reality is a perpetually changing and fluent flux) to explicate the dynamically emergent nature of human consciousness.

It was enunciated that $\mathrm{CHT}$ is predicated on non-reductive, and historical materialism in that it holds that human consciousness, for its genesis and functionality, is causally dependent on the material and temporal activity embedded in the everyday world; but as an ontologically emergent phenomenon it has autonomous and objective properties, and consequently causal power sui generis over and above any material activity. It was also discussed that the causal nexus between human consciousness and socio-historically constructed physical world are reciprocal but asymmetrical. For Vygotsky a human's material and ongoing activity presupposes both its past and its future. Human consciousness is not a pre-given and equifinal actuality which unfolds timelessly; it is a multifaceted, contingent and time-dependent possibility which is constructed and emerges through human agency over different timescales. It was also demonstrated how and why Vygotskian CHT accounts for the dynamic, complex, emergent, time-dependent, originally 
material and purposive nature of human consciousness by a dialectical synthesis of the underlying axioms of organicism and contextualism world hypotheses.

\section{Acknowledgment}

This article is dedicated to Prof. Behrooz Azabdaftari, emeritus professor of University of Tabriz (Iran), who eruditely introduced Vygotskian cultural-historical theory to me while I was an undergraduate student in English language and literature program. I would like to thank Hannele Dufva for her helpful comments. My heartfelt appreciation is due to Willis F. Overton, Michael Cole, and Michael Glassman for their continual support, illuminating remarks, and insightful suggestions as well as for carefully reading and commenting on earlier versions of this article. Special thanks should go to numerous anonymous reviewers for their insightful and constructive comments, many valuable suggestions, and tremendously useful feedback on earlier drafts of this article. James P. Lantolf deserves a special word of thanks for acting as my sponsor faculty at the Center for Language Acquisition (CLA), the Pennsylvania State University while final revision of this article was afoot. I gratefully acknowledge practical advice and positive encouragement of Sune Vork Steffensen, Mika Lähteenmäki, Edward K. Morris, and Hayne W. Reese. I also owe special thanks to the editor of the journal, Larry Nucci, for his support and helpful suggestions. The remaining errors, misconceptions, and misapprehensions, needless to say, remain with me only. 


\section{References}

Ablowitz, R. (1939). The theory of emergence. Philosophy of Science, 6, 1-16.

Ackoff, R. L. \& Emery, F. E. (1972). On purposeful systems. London: Tavistock Publications.

Adoratsky, V. (1934). Dialectical materialism. New York: International Publishers.

Afanasyev, V.G. (1980). Marxist philosophy. Moscow: Progress Publishers.

Altman, I., \& Rogoff, B. (1987). World views in psychology: Trait, interactional, organismic, and transactional perspectives (pp.7-40). In D. Stokols \& I. Altman (Eds.). Handbook of environmental psychology (Vol. 1). New York: Wiley.

Arievitch, I. M. \& Stetsenko, A. (2014). The "magic of signs": Developmental trajectory of cultural mediation. In Yasnitsky, A., van der Veer, R., \& Ferrari, M. (Eds.). The Cambridge handbook of cultural-historical psychology. (pp. 217-244). Cambridge: Cambridge University Press.

Ayala, F. J. (1970). Teleological explanations in evolutionary biology. Philosophy of Science, 37, 115.

Bakhurst, D. (1991). Consciousness and revolution in Soviet philosophy: From the Bolsheviks to Evald Ilyenkov. Cambridge: Cambridge University Press.

Baltes, P. B., Reese, H. W., \& Nesselroade, J. R. (1977). Life-span developmental psychology: Introduction to research methods. Monterey, California: Wadsworth Publishing Company.

Baxter, L. A., \& Montgomery, B. M. (1996). Relating: Dialogues and dialectics. New York: Guildford Press.

Bernstein, R. J. (1971). Praxis and action: Contemporary philosophies of human activity. Philadelphia: University of Pennsylvania Press. 
Bertalanffy, L. von. (1968).General system theory: Foundations, development, applications. New York: Brazilian.

Bickhard, M. H. (2008). Are you social? The ontological and developmental emergence of the person. In U. Mueller, J. I. M. Carpendale, N. Budwig \& B. Sokol (Eds.), Social life and social knowledge: Toward a process account of development (pp. 17-42). New York: Taylor \& Francis Group.

Bidell, T. (1988). Vygotsky, Piaget and the dialectic of development. Human Development, 31, 329345.

Bunge, M. (1960). Levels: A semantical preliminary. The Review of Metaphysics, 13, 396-406.

Bunge, M. (1962). Causality: The place of the causal principle in modern science. New York: World Publishing.

Bunge, M. (1981). Scientific materialism. Boston: D. Reidel Publishing Company.

Burtt, E. A. (1943). The status of 'World Hypotheses'. Philosophical Review, 52, 590-601.

Campbell, R. (2009). A processed-based model for an interactive ontology. Synthese, 166, 453-477.

Capaldi, E.J., \& Proctor, R.W. (1994). Contextualism: Is the act in context the appropriate metaphor for scientific psychology? Psychonomic Bulletin \& Review, 1, 239-249.

Cole, M. (1996). Cultural psychology: A once and future discipline. Cambridge, MA: Harvard University Press.

Cole, M. (1997). Cultural mechanisms of cognitive development in: E. Amstel \& K. A. Renniger (Eds.), Change and development: issues of theory, method, and application (pp. 245-263). Mahwah, NJ: Lawrence Erlbaum. 
Cole, M., \& Engeström, Y. (1993). A cultural-historical approach to distributed cognition. In G. Salomon (Ed.), Distributed cognitions: Psychological and educational considerations (pp. 1-46). New York: Cambridge University Press.

Cole, M., \& Wertsch, J. V. (1996). Beyond the individual-social antinomy in discussions of Piaget and Vygotsky. Human Development, 39, 250-256.

Cole, M., \& Gajdamaschko, N. (2010).Vygotsky and context: Toward a resolution of theoretical disputes. In Kirschner, S., \& Martin, J. (Eds.). The sociocultural turn in psychology: The contextual emergence of mind and self. New York: Columbia University Press.

Cole, M., \& Hatano, G. (2007). Cultural-historical activity theory: Integrating phylogeny, cultural history, and ontogenesis in cultural psychology. In S. Kitayama \& D. Cohen (Eds.), Handbook of cultural psychology (pp. 109-135). New York, NY: Guilford.

Collins, C. (2000). Vygotsky on language and social consciousness: Underpinning the use of Voloshinov in the study of popular protest. Historical Materialism, 7, 41-69.

Davydov, V. V., \& Radzikhovskii, L. A. (1985). Vygotsky's theory and the activity-oriented approach in psychology. In J. V. Wertsch (Ed.), Culture, communication, and literacy: Vygotskian perspectives (pp. 35-65). New York: Cambridge University Press.

Dixon, R. A., \& Lerner, R. M. (1984). History and systems in developmental psychology. In M. Bornstein \& M. Lamb (Eds.), Developmental psychology: An advanced textbook (pp. 1-35). Hillsdale, NJ: Lawrence Erlbaum Associates.

Engeström, Y. (1987). Learning by expanding: An activity-theoretical approach to developmental research. Helsinki: Orienta-Konsultit Oy.

Engeström, Y., Miettinen, R., \& Punamäki, R. (Eds.) (1999). Perspectives on activity theory Cambridge: Cambridge University Press. 
Fedoseyev, P. N. (1977). General methodological problems. In Philosophy in the USSR: Problems of dialectical materialism (pp. 7-21). Moscow: Progress Publishers.

Feibleman, J. K. (1954). Theory of integrative levels. The British Journal for the Philosophy of Science, 5, 59-66.

Ford, D.H., \& Lerner, R.M. (1992). Developmental systems theory: An integrated approach. Newbury Park, CA: Sage

Glassman, M. (2000). Negation through history: Dialectics and human development. New Ideas in Psychology, 18, 1-22.

Harré, R., \& Secord, P. F. (1972). The explanation of social behaviour. Oxford, England: Basil Blackwell.

Hayes, S. C., Hayes, L. J., \& Reese, H. W. (1988). Finding the philosophical core: A review of Stephen C. Pepper's World Hypotheses: A study in evidence. Journal of Experimental Analysis of Behavior, 50, 97-111.

Hofstadter, A. (1941). Objective teleology. The Journal of Philosophy, 37, 29-39.

Ilyenkov, E. V. (1977). Dialectical logic: Essays in its history and theory (Trans H.C. Creighton). Moscow: Progress Publishers.

Ilyenkov, E. (2012). Dialectics of the ideal. Historical Materialism, 20, 149-193.

Jacoby, R. (1970). Lenin and Luxemburg: Negation in theory and praxis. Radical America, 4, 21-31.

Karimi-Aghdam, S. (2016a). A dialectical reading of dynamic systems theory: Transcending socialized cognition and cognized social dualism in L2 studies. Language and Sociocultural Theory, 3, 55-82. 
Karimi-Aghdam, S. (2016b). Moving toward a supertheory for all seasons: Dialectical dynamic systems theory and sociocultural theory - A reply to McCafferty (2016). Language and Sociocultural Theory, 3, 89-96.

Karimi-Aghdam, S. (forthcoming). Zone of Proximal Development (ZPD) as an emergent system: A dynamic systems theory perspective. Integrative Psychological and Behavioral Science.

Karimi-Aghdam, S., Dufva, H., \& Lähteenmäki, M. (forthcoming). Dancing with alternative lyrics: Integrating sociocultural, dialogical, distributed and dynamical conceptualization of language and its development for L2 studies. Finnish Association of Applied Linguistics (AFinLA) Yearbook 74 .

Kendler, T. S. (1986). World views and the concept of development: A reply to Lerner and Kauffman. Developmental Review, 6, 80-95.

Kilminster, R. (1979). Praxis and method. A sociological dialogue with Lukács, Gramsci and the early Frankfurt school. London: Routledge and Kegan Paul.

Kojève, A. (1969). Introduction to the reading of Hegel: Lectures on the phenomenology of spirit (James H. Nichols, Jr., Trans.). New York: Basic Books, Inc. Publishers.

Kozulin, A. (1986). The concept of activity in Soviet psychology: Vygotsky, his disciples and critics. American Psychologist, 41, 264.

Kozulin, A. (1990). Vygotsky's psychology: A biography of ideas. New York: Harvester Wheatsheaf. Langer, J. (1969). Theories of development. New York: Holt, Rinehart \& Winston.

Leary, D. E. (Ed.). (1994). Metaphors in the history of psychology. Cambridge University Press.

Lefebvre, H. (1968). Dialectical materialism, (Trans J. Sturrock). London: Jonathan Cape. 
Lektorsky, V. A. (1977). The dialectics of subject and object and some problems of the methodology of science. In Philosophy in the USSR: Problems of dialectical materialism (pp. 100-112). Moscow: Progress Publishers.

Leont'ev, A. N. \& Luria, A. R. (1956). Psikhologicheskie vozzreniya L.S. Vygotskogo. (The psychological views of L.S. Vygotsky.) In L.S. Vygotsky, Izbrannye psikhologicheskie issledovaniya (Selected psychological investigations.) Moscow: Izdetel'stvo Akademii Pedagogicheskikh Nauk RSFSR.

Leont'ev, A. N., \& Luria, A. R. (1968). The psychological ideas of L. S. Vygotskii. In B. B. Wolman (Ed.), Historical roots of contemporary psychology (pp. 338-367). New York: Harper \& Row Publishers.

Lerner, R. M. (1978). Nature, nurture, and dynamic interactionism. Human Development, 21, 1-20.

Lerner, R. M. (1986). Concepts and theories of human development (2nd ed.). New York: Random House.

Lerner, R. M. (1992). Dialectics, developmental contextualism, and the further enhancement of theory about puberty and psychosocial development. The Journal of Early Adolescence, 12, 366388.

Lerner, R. M. (1996). Relative plasticity, integration, temporality, and diversity in human development: A developmental contextual perspective about theory, process, and method. Developmental Psychology, 32, 781.

Lerner, R. M., Hultsch, D. F., \& Dixon, R. A. (1983). Contextualism and the character of developmental psychology in the 1970s. Annals of the New York Academy of Sciences, 412, 101128. 
Lerner, R. M., \& Kauffman, M. B. (1985). The concept of development in contextualism. Developmental Review, 5, 309-333.

Lerner, R. M., \& Kauffman, M. B. (1986). On the metatheoretical relativism of analyses of metatheoretical analyses: A critique of Kendler's comments. Developmental Review, 6, 96-106.

Lerner, R. M., \& Overton, W. F. (2008). Exemplifying the integrations of the relational developmental system: Synthesizing theory, research, and application to promote positive development and social justice. Journal of Adolescent Research, 23, 245-255.

Levins, R. (1998). Dialectics and systems theory. Science \& Society, 62, 375-399.

Lukasiewicz, J., \& Wedin, V. (1971). On the principle of contradiction in Aristotle. The Review of Metaphysics, 24, 485-509.

Luria, A. R. (1979). The making of mind: A personal account of Soviet psychology. (M. Cole \& S. Cole, Trans.). Cambridge, MA: Harvard University Press.

Luria, A. R. (1981). Language and cognition. Washington, DC: Winston

Lyddon, W. J. (1989). Root metaphor theory: A philosophical framework for counseling and psychotherapy. Journal of Counseling \& Development, 67, 442-448.

Miller, R. (2011). Vygotsky in perspective. New York: Cambridge University Press.

Minton, H. L. (1992). Root metaphors and the evolution of American social psychology. Canadian Psychology, 33(3), 547-553.

Moll, I. (1994). Reclaiming the natural line in Vygotsky's theory of cognitive development. Human Development, 37, 333-342.

Moravcsik, J. M., (1974). Aristotle on adequate explanations, Synthese, 28: 3-17.

Morris, E. K. (1988). Contextualism: The world view of behavior analysis. Journal of Experimental Child Psychology, 46, 289-323. 
Morris, E. K. (1993). Mechanism and contextualism in behavior analysis: Just some observations. The Behavior Analyst, 16, 255-268.

Morris, E. K. (1997). Some reflections on contextualism, mechanism, and behavior analysis. The Psychological Record, 47, 529.

Moshman, D. (1982). Exogenous, endogenous, and dialectical constructivism. Developmental Review, 2, 371-384.

Naugle, D. K. (2002). Worldview: The history of a concept. Cambridge: William B. Eerdmans Publishing Company.

Novikoff, A. B. (1945a). The concept of integrative levels and biology. Science, 101, 209-215.

Novikoff, A. B. (1945b). Continuity and discontinuity in evolution. Science, 101, 405-406.

Ollman, B. (1976). Alienation (2nd ed.). Cambridge, England: Cambridge University Press.

O'Connor, B. (1999). The concept of mediation in Hegel and Adorno. Hegel Bulletin, 20, 84-96.

Overton, W. F. (1984). World views and their influence on psychological theory and research: KuhnLakatos-Laudan. In H. W. Reese (Ed.) Advances in child development and behavior (Vol. 18, pp. 191-226). New York: Academic Press.

Overton, W. F. (1991). The structure of developmental theory. In H. W. Reese (Ed.), Advances in child development and behavior. Vol. 23 (pp. 1-37). New York: Academic Press.

Overton, W. F. (1998). Developmental psychology: Philosophy, concepts, and methodology. In R. M. Lerner (Ed.) Theoretical models of human development.Vol.1. Handbook of child psychology, (pp. 107-188). (5th ed.), Editor-in-Chief: William Damon. New York: Wiley.

Overton, W. F. (2007). A coherent metatheory for dynamic systems: Relational organicismcontextualism. Human development, 50, 154-159. 
Overton, W. F. (2013a). Relationism and relational developmental systems: A paradigm for developmental science in the post-Cartesian era. Advances in Child Development and Behavior, $44,21-64$.

Overton, W. F. (2013b). A new paradigm for developmental science: Relationism and relationaldevelopmental systems. Applied Developmental Science, 17, 94-107.

Overton, W. F. (2013c). Relational developmental systems and developmental science: A focus on methodology. In Molenaar, P. C. M., Lerner, R. M. and Newell, K. M. (eds). Handbook of developmental systems theory and methodology. (pp. 19-65). New York, NY: Guilford Press.

Overton, W. F. (2014). Relational developmental systems and developmental science: A focus on methodology. In Molenaar, P. C. M., Lerner, R. M., \& Newell, K. (Eds.). Handbook of developmental systems theory and methodology. New York, NY: Guilford.

Overton, W.F. (2015). Process and relational developmental systems. In W.F. Overton \& P.C. Molenaar (Eds.), Handbook of child psychology and developmental science. Vol. 1: Theory and method (7th ed., pp. 9-62). Editor-in-chief: R. M. Lerner. Hoboken, NJ: Wiley.

Overton, W. F., \& Lerner, R. M. (2012). Relational-developmental-systems: paradigm for developmental science in the postgenomic era. Brain and Behavioral Science, 35, 375-376.

Overton, W. F. \& Lerner, R. M. (2014). Fundamental concepts and methods in developmental science: A relational perspective. Research in Human Development. 11, 63-73,

Overton, W. F., \& Ennis, M. D. (2006). Cognitive-developmental and behavior-analytic theories: Evolving into complementarity. Human Development, 49, 143-172.

Overton, W. F., \& Reese, H. W. (1973). Models of development: Methodological implications. In J. R. Nesselroade \& H. W. Reese (Eds.), Life span developmental psychology: Methodological issues (pp. 65-86). New York: Academic Press. 
Overton, W. F., \& Reese, H. W. (1981). Conceptual prerequisites for an understanding of stabilitychange and continuity-discontinuity. International Journal of Behavioral Development, 4, 99123.

Pepper, S. C. (1926). Emergence. The Journal of Philosophy, 23(9), 241-245.

Pepper, S. C. (1928). Philosophy and metaphor. The Journal of Philosophy, 25, 130-132.

Pepper, S. C. (1934).The conceptual framework of Tolman's purposive behaviorism. Psychological Review, 41, 108-133.

Pepper, S. C. (1935). The root of metaphor theory of metaphysics. The Journal of Philosophy, 32, 365-374.

Pepper, S. C. (1942). World hypotheses: A study in evidence. Berkeley: University of California Press.

Pepper, S. C. (1943a). Metaphysical method. Philosophical Review, 52, 252-269.

Pepper, S. C. (1943b). The status of "World Hypotheses": A rejoinder. Philosophical Review, 52, 602- 604 .

Pepper, S. C. (1966). Concept and quality. La Salle, Illinois: Open Court.

Pepper, S. C. (1973). Metaphor in philosophy. In P. P. Wiener (Editor-in-Chief), Dictionary of history of ideas, Volume 3 (pp. 196-201). New York: Charles Scribner's Sons.

Popper, K. R. (1940). What is dialectic? Mind, 49, 403-426.

Ratner, C. (1991). Vygotsky's sociohistorical psychology and its contemporary applications. New York: Plenum.

Ratner, C. (2016). Culture-centric vs. person-centered cultural psychology and political philosophy. Language and Sociocultural Theory, 3, 11-25.

Reese, H. W. (1993). Comments about Morris's paper. The Behavior Analyst, 16, 67-74. 
Reese, H. W., \& Overton, W. F. (1970). Models of development and theories of development. In L. R. Goulet \& P. B. Baltes (Eds.), Lifespan developmental psychology: Research and theory (pp. 115-145). New York: Academic Press.

Rescher, N. (1996). Process metaphysics: An introduction to process philosophy. Albany: State University of New York Press.

Riegel, K. F. (1975). Toward a dialectical theory of development. Human Development, 18, 50-64.

Riegel, K. F. (1976). The dialectics of human development. American Psychologist, 31, 689.

Riegel, K. F. (1978). Psychology mon amour: A countertext. Houghton Mifflin.

Riegel, K. F. (1979). Foundations of dialectical psychology. New York: Academic Press.

Rosenblueth, A., Wiener, N. \& Bigelow, J. (1943) Behavior, purpose and teleology. Philosophy of Science, 10, 18-24.

Rubinstein, S.L. (1957). Questions of psychological theory. In B. Simon (Ed.), Psychology in the Soviet Union (pp. 264-278). London: Routledge \& Kegan Paul Ltd.

Rogoff, B. (1982). Integrating context and cognitive development. In M. E. Lamb \& A. L. Brown (Eds.), Advances in developmental psychology. Vol. 2 (pp. 125-170). Hillsdale, NJ: Erlbaum.

Rogoff, B. (1988). Commentary on Vygotsky, Piaget and the dialectic of development. Human Development, 31, 346-348.

Rogoff, B. (1992). Three ways to relate person and culture: Thoughts sparked by Valsiner's review of Apprenticeship in thinking. Human Development, 35, 316-320.

Rosnow, R. L., \& Georgoudi, M. (1986). The spirit of contextualism. In R. L. Rosnow \& M. Georgoudi (Eds.), Contextualism and understanding in behavioral science: Implications for research and theory (pp. 3-22). New York: Praeger.

Roth, W. M., (2016).Concrete human psychology. New York: Routledge. 
Sawyer, R. K. (2002a). Emergence in psychology: Lessons from the history of non-reductionist science. Human Development, 45, 2-28.

Sawyer, R. K. (2002b). Unresolved tensions in sociocultural theory: Analogies with contemporary sociological debates. Culture \& Psychology, 8, 283-305.

Schaffner, K. H. (1967). Approaches to reduction. Philosophy of Science, 34, 137-147.

Schneirla, T. C. (1952). A consideration of some conceptual trends in comparative psychology. Psychosocial Bulletin, 49, 559-597.

Shirokov, M. (1937). A textbook of Marxist philosophy (translated and edited by A.C. Moseley \& J. Lewis). London: The Camelot Press Ltd.

Smith, M. B. (1988). Beyond Aristotle and Galileo: Toward a contextualized psychology of persons. Theoretical and Philosophical Psychology, 8, 2-15.

Stace, W. T. (1939). Novelty, indeterminism, and emergence. The Philosophical Review, 48, 296310.

Stace, W. T. (1955). The philosophy of Hegel. New York, NY: Dover.

Staddon, J. E. R. (1993). Pepper with a pinch of psalt. Behavior Analyst, 16, 245-250.

Stetsenko, A. (2005). Activity as object-related: Resolving the dichotomy of individual and collective planes of activity. Mind, Culture, and Activity, 12, 70-88.

Stetsenko, A. (2008). From relational ontology to transformative activist stance on development and learning: expanding Vygotsky's (CHAT) project. Cultural Studies of Science Education, 3, 471491.

Stetsenko, A. (2009). Vygotsky and the conceptual revolution in developmental sciences: Towards a unified (non-additive) account of human development. In M. Fleer, M. Hedegaard, J. Tudge \& 
A. Prout (Eds.) World Year Book of Education. Constructing childhood: Global-local policies and practices (pp. 125-142). Routledge.

Stetsenko, A., \& Arievitch, I. M. (2004). The self in cultural-historical activity theory reclaiming the unity of social and individual dimensions of human development. Theory \& Psychology, 14, 475-503.

Stetsenko, A. \& Arievitch, I.M. (2010). Cultural-historical activity theory (CHAT): foundational worldview, major principles and the relevance of sociocultural context. In S. Kirschner \& J. Martin (Eds.), The sociocultural turn in psychology: Contemporary perspectives on the contextual emergence of mind and self. New York: Columbia University Press.

Super, C. M., \& Harkness, S. (2003). The metaphors of development. Human Development, 46, 3-23.

Taylor, C. (1975). Hegel. Cambridge: Cambridge University Press.

Taylor, R. (1966). Action and purpose. Englewood Cliffs, N.J.: Prentice-Hall.

Teplov, B.M. (1957). Objective method in psychology. In B. Simon (Ed.). Psychology in the Soviet Union (pp. 246-263). London: Routledge \& Kegan Paul Ltd.

Tobach, E., \& Greenberg, G. (1984). The significance of T. C. Schneirla's contribution to the concept of levels of integration. In G. Greenberg \& E. Tobach (Eds.), Behavioral evolution and integrative levels (pp. 1-7). Hillsdale, NJ: Erlbaum.

Tolman, C. (1983). Further comments on the meaning of 'dialectic'. Human Development, 26, 320324

Tucker, R. (1961). Philosophy and myth in Karl Marx. Cambridge, Cambridge University Press

Valsiner, J., \& van der Veer, R. (2014). Encountering the border: Vygotsky's zona blizaishego razvitia and its implications for theories of development. In A. Yasnitsky \& R. van der Veer 
(Eds.). Handbook of cultural-historical psychology (pp. 148-173).Cambridge: Cambridge University Press.

Van der Veer, R. \& Valsiner, J. (1991). Understanding Vygotsky: A quest for synthesis. Oxford: Blackwell.

Van der Veer, R. \& Valsiner, J. (1994). The Vygotsky reader. Oxford: Blackwell.

Von Wright, G.H. (1971). Explanation and understanding. London: Routledge\& Kegan Paul.

Vygotsky, L. S. (1978). Mind in society: The development of higher psychological processes.

Cambridge, MA: Harvard University Press (M. Cole, V. John-Steiner, S. Scribner, \& E. Souberman, Eds. and Trans.; original works published 1930-1935).

Vygotsky, L. (1979). Consciousness as a problem in the psychology of behavior. Journal of Russian and East European Psychology, 17, 3-35.

Vygotsky, L.S. (1981a). The instrumental methods in psychology. In J.V. Wertsch (Ed.), The concept of activity in Soviet psychology (pp.134-143). Armonk, NY: Sharpe.

Vygotsky, L.S. (1981b). The genesis of higher mental functions. In J.V. Wertsch (Ed.), The concept of activity in Soviet psychology (pp.144-188). Armonk, NY: Sharpe.

Vygotsky, L.S. (1986). Thought and language. (A. Kozulin, Ed. \& Trans.). Cambridge, MA: MIT Press.

Vygotsky, L. S. (1987). Thinking and speech. In L. S. Vygotsky, R. W. Rieber (Series Eds.), \& A. S. Carton (Vol. Ed.), The collected works of L. S. Vygotsky. Vol. 1: Problems in general psychology (N. Minick, Trans.). New York: Plenum.

Vygotsky, L. S. (1989). Concrete human psychology. Soviet Psychology, 27, 53-77. 
Vygotsky, L. S. (1993). The collected works of LS Vygotsky, Volume 2: The fundamentals of defectology (RW Rieber, \& AS Carton, Eds., \& JE Knox \& CB Stevens, Trans.). New York: Plenum.

Vygotsky, L. S. (1997a). On psychological systems. In R. W. Rieber \& J. Wollock (Eds.), Collected works of L. S. Vygotsky: Vol. 3. Problems of the theory and history of psychology (pp. 91-107). New York: Plenum.

Vygotsky, L. S. (1997b). The collected works of LS Vygotsky: Vol. 4. The history of the development of higher mental functions (M. Hall, Trans.; RW Rieber, Ed.). New York: Plenum.

Vygotsky, L. S. (1997c). The problem of the development of higher mental functions. In R. W. Rieber (Ed.), The collected works of L. S. Vygotsky: Vol. 4. The history of the development of higher mental functions: Cognition and language (pp. 1-26). New York: Plenum Press.

Vygotsky, L. S. (1998). The collected works of L. S. Vygotsky (M. J. Hall, Trans., Vol. 5, Child Psychology). New York: Kluwer Academic/Plenum.

Vygotsky, L. S. (1999). Analysis of sign operations in the child. Vol. 6. In R. W. Rieber (Ed.), Scientific legacy, Collected works of L. S. Vygotsky (pp. 45-56). New York: Plenum. (Original work published 1982-1984)

Vygotsky, L. S. (2012). The science of psychology. Journal of Russian and East European Psychology, 50, 85-106.

Vygotsky, L. S., \& Luria, A. (1994). Tool and symbol in child development. In R. van der Veer \& J. Valsiner (Eds.), The Vygotsky reader (pp. 99-174). Cambridge, MA: Blackwell.

Wertsch, J. V. (Trans. \& Ed.). (1981). The concept of activity in Soviet psychology. New York: M. E. Sharpe 
Wertsch, J. V. (1985). Vygotsky and the social formation of mind. Cambridge, MA: Harvard University Press.

Wertsch, J., ed. (1985). Culture, communication, and cognition: Vygotskian perspectives. Cambridge: Cambridge University Press.

Wertsch, J.V. (1991a). Voices of the mind: A sociocultural approach to mediated action. Cambridge, MA: Harvard University Press.

Wertsch, J. V. (1991b). A sociocultural approach to socially shared cognition In L. B. Resnick, J. M. Levine, \& S. D. Teasley (Eds.), Perspectives on socially shared cognition (pp. 85-100). Washington, DC: American Psychological Association.

Wertsch, J.V. (1994). The primacy of mediated action in sociocultural studies. Mind, Culture \& Activity, 1, 202-208.

Witherington, D. C. (2007). The dynamic systems approach as metatheory for developmental psychology. Human Development, 50, 127-153.

Witherington, D. C., \& Heying, S. (2013). Embodiment and agency: Toward a holistic synthesis for developmental science. In R. M. Lerner \& J. B. Benson (Eds.), Advances in child development and behavior: Vol. 44: Embodiment and epigenesis: Theoretical and methodological issues in understanding the role of biology within the relational developmental system (pp. 161-192). Oxford, UK: Academic Press.

White, P. A. (1990). Ideas about causation in philosophy and psychology. Psychological Bulletin, $108,3-18$.

Wozniak, R. (1975). Dialecticism and structuralism: The philosophical foundation of Soviet psychology and Piagetian cognitive developmental theory. In K. F. Riegel \& G. C. Rosenwald (Eds.), Structure and transformation (pp. 61-81). New York: Wiley. 
Yaroshevsky, M.G. (1968). I. M. Sechenov - the founder of objective psychology. In: Benjamin B. Wolman (ed.), Historical roots of contemporary psychology (77-110). New York: Harper \& Row.

Zaporozhets, A. V. (2003). Problems in the psychology of activity. Journal of Russian and East European Psychology, 40, 47-52.

Zavershneva, E. (2014). The problem of consciousness in Vygotsky's cultural-historical psychology. In Yasnitsky, A., van der Veer, R., \& Ferrari, M. (Eds.). The Cambridge handbook of culturalhistorical psychology. (pp. 63-98). Cambridge: Cambridge University Press. 